OPEN ACCESS

Edited by:

Gustavo Henrique Goldman, Universidade de São Paulo, Brazil

Reviewed by:

Antonella Amicucci,

Università degli Studi di Urbino

Carlo Bo, Italy

Antonietta Mello,

Istituto per la Protezione Sostenibile delle Piante (IPSP), Italy

${ }^{*}$ Correspondence:

Xiaolin $\mathrm{Li}$

kerrylee_tw@sina.com

${ }^{\dagger}$ These authors have contributed equally to this work

Specialty section:

This article was submitted to Fungi and Their Interactions,

a section of the journal

Frontiers in Microbiology

Received: 15 March 2018

Accepted: 28 August 2018 Published: 18 September 2018

Citation:

Li Q, Yan L, Ye L, Zhou J, Zhang B, Peng W, Zhang $X$ and Li X (2018) Chinese Black Truffle (Tuber indicum) Alters the Ectomycorrhizosphere

and Endoectomycosphere Microbiome and Metabolic Profiles of the Host Tree Quercus aliena.

Front. Microbiol. 9:2202.

doi: 10.3389/fmicb.2018.02202

\section{Chinese Black Truffle (Tuber indicum) Alters the Ectomycorrhizosphere and Endoectomycosphere Microbiome and Metabolic Profiles of the Host Tree Quercus aliena}

\author{
Qiang $\mathrm{Li}^{1,2 t}$, Lijuan Yan ${ }^{3 t}$, Lei Ye ${ }^{1}$, Jie Zhou' ${ }^{1}$, Bo Zhang ${ }^{1}$, Weihong Peng', \\ Xiaoping Zhang ${ }^{1}$ and Xiaolin $\mathrm{Li}^{1 *}$ \\ 'Soil and Fertilizer Institute, Sichuan Academy of Agricultural Sciences, Chengdu, China, ${ }^{2}$ Key Laboratory of Bio-Resource \\ and Eco-Environment of Ministry of Education, College of Life Sciences, Sichuan University, Chengdu, China, ${ }^{3}$ Aquatic \\ Geomicrobiology, Institute of Biodiversity, Friedrich Schiller University Jena, Jena, Germany
}

Truffles are one group of the most famous ectomycorrhizal fungi in the world. There is little information on the ecological mechanisms of truffle ectomycorrhizal synthesis in vitro. In this study, we investigated the ecological effects of Tuber indicum - Quercus aliena ectomycorrhizal synthesis on microbial communities in the host plant roots and the surrounding soil using high-throughput sequencing and on the metabolic profiles of host plant roots using metabolomics approaches. We observed an increase in the diversity and richness of prokaryotic communities and a decrease in richness of fungal communities in the presence of $T$. indicum. The microbial community structures in the host roots and the surrounding soil were altered by ectomycorrhizal synthesis in the greenhouse. Bacterial genera Pedomicrobium, Variibacter, and Woodsholea and fungal genera Aspergillus, Phaeoacremonium, and Pochonia were significantly more abundant in ectomycorhizae and the ectomycorrhizosphere soil compared with the corresponding T. indicum-free controls $(P<0.05)$. Truffle-colonization reduced the abundance of some fungal genera surrounding the host tree, such as Acremonium, Aspergillus, and Penicillium. Putative prokaryotic metabolic functions and fungal functional groups (guilds) were also differentiated by ectomycorrhizal synthesis. The ectomycorrhizal synthesis had great impact on the measured soil physicochemical properties. Metabolic profiling analysis uncovered 55 named differentially abundant metabolites between the ectomycorhizae and the control roots, including 44 upregulated and 11 downregulated metabolites. Organic acids and carbohydrates were two major upregulated metabolites in ectomycorhizae, which were found formed dense interactions with other metabolites, suggesting their crucial roles in sustaining the metabolic functions in the truffle ectomycorrhization system. This study revealed the effects of truffle-colonization on the metabolites of ectomycorrhiza and illustrates an interactive network between truffles, the host plant, soil and associated microbial communities, shedding light on understanding the ecological effects of truffles.

Keywords: truffle, ectomycorrhiza, microbial diversity, soil properties, metabolomics 


\section{INTRODUCTION}

Mycorrhizae are present in more than $80 \%$ of plant species, play an important role in the maintenance of the forest ecosystem and in global carbon and phosphorus cycling (Li et al., 2006; Franklin et al., 2014). Mycorrhizae can enhance nutritional values and primary productivity and modulate pest and stress resistance of the host plants (Selosse et al., 2006; Chen et al., 2017; Pérezde-Luque et al., 2017). On the other hand, mycorrhizal fungus is supplied with carbohydrates by the host plants (Doidy et al., 2012; Ait Lahmidi et al., 2016). Mycorrhizae are commonly divided into ectomycorrhizae (ECM) and endomycorrhizae (Allen et al., 2003). It is known that colonization of plant tissues by mycorrhizal fungus results in an increase of sucrose catabolism, an increase of some organic acids, and a decrease of some amino acids (Laparre et al., 2014; Saia et al., 2015). In spite of the importance of ECM associations for plant vitality, we have little information on the molecular and physiological mechanisms of ectomycorrhizal synthesis (Larsen et al., 2011; Tschaplinski et al., 2014; Martin et al., 2016). Most of our current knowledge are based on the studies of plants that interact with arbuscular mycorrhizae (AM), which may differ in many respects of those that interact with EM fungi (Luo et al., 2009; Vayssieres et al., 2015; Watts-Williams and Cavagnaro, 2015).

In the post-genomic era of systems biology, metabolomics approaches gain their popularity to assess the metabolomes of organisms in a comprehensive and unbiased way and to uncover unknown regulation patterns (Rasmussen et al., 2012). However, most knowledge on the modulation from diverse metabolites are dependent on the studies of a few model plant species and it is difficult to transfer the findings from these models to other plant systems (Schweiger et al., 2014). Besides, targeted analyses which focus on the analysis of a few well-characterized metabolites fail to complete the full metabolic picture of plant responses (Schweiger et al., 2014; Schweiger and Muller, 2015). Metabolic profiling is expected to enhance the insight into the ECM symbiotic interactions with adequate resolution (Vayssieres et al., 2015). Being downstream of the transcriptome and proteome, the metabolome is closest to diverse biological functions and thus decisive for ecological interactions between the host plants and the mycorrhizal fungi, for example, truffles (de Vries et al., 2011).

Truffles, belonging to the Tuber genus (Ascomycota, Pezizales), are a group of fungi that produce hypogeous fruiting bodies (Poma et al., 2006; Benucci and Bonito, 2016). Their fruiting bodies are considered very precious and delicious food because of their unique fragrance (Pacioni et al., 2014; Schmidberger and Schieberle, 2017). Tuber spp. is an ectomycorrhizal fungus, which does not produce fruiting bodies without symbiotic association with its host plants. Truffles can form a symbiotic relationship with several genera of trees, including Abies, Corylus, Pinus, and Quercus (Zitouni-Haouar et al., 2014; Marozzi et al., 2017). The black truffle (Tuber melanosporum) and the white truffle (T. magnatum) have been highly valued in the European market because of their unique flavors (Vita et al., 2015; Payen et al., 2016). Tuber indicum, commonly known as the Chinese black truffle, is the main commercial truffle species in China (Garcia-Montero et al., 2008). It shows a close phylogenetic relationship with T. melanosporum and has similar morphological features (Chen et al., 2011). Ribonuclease and polysaccharides isolated from their fruiting bodies or fermentation systems showed strong antitumor, antioxidant, and antiproliferative activities (Xiao et al., 2014; Zhao et al., 2014). Due to the decreased yield of wild truffles, the synthesis and artificial cultivation of these ectomycorrhizae have attracted more and more attention. At present, T. indicum ectomycorrhizae have been successfully synthesized with Chinese indigenous plants, such as Pinus armandii and Castanea mollissima (Geng et al., 2009). The P. armandii and Quercus aliena mixed forest is one of the major forest types in many areas of China (Yu et al., 2014). Q. aliena is widely distributed in China and has a strong environmental adaptability. Its roots are well-developed and colonized by various mycorrhizae. T. indicum was successfully cultivated in artificial truffle orchards with $Q$. aliena as the host tree in China. However, the plant's metabolic components in response to the ectomycorrhizal synthesis, especially to truffle ectomycorrhizal synthesis, remain unknown, which limits our understanding of the interactive relationships between this important ectomycorrhizal fungus ( $T$. indicum) and its host plants (Splivallo et al., 2009).

As one of the most important members of the ectomycorrhizal fungi, a truffle plays an important role in the terrestrial ecosystems. Some black truffles often form brûlé (an area devoid of herbaceous cover) around the host trees, affecting the biodiversity of bacteria and fungi in the brûlé area (Mello et al., 2013, 2015; De Miguel et al., 2014). Being dominant, Tuber spp. is predicted to affect the associated soil fungal communities (Napoli et al., 2010; Streiblova et al., 2012), plausibly leading to the formation of the brûlé region. Different truffle species were found to exert different competitive effects on other mycobionts (Garcia-Barreda and Reyna, 2012; Taschen et al., 2015). ECM can be beneficial to plant productivity by enhancing plant growth or resistance to abiotic stress (Alvarez-Lafuente et al., 2018). They also can improve water and nitrogen acquisition of the host plants and play a key role in the nutrition acquisition of forest trees (Liese et al., 2018). The colonization of ECM induces higher soil porosities, which has been proven to play a crucial role in achieving success in black truffle plantations (Alonso Ponce et al., 2014). Our previous studies have shown that the growth of $T$. indicum alters the microbial communities of ectomycorrhizosphere soil and ectomycorrhizae of $P$. armandii (Li et al., 2017).

However, the effects of the truffle ectomycorrhizal symbiosis on soil microbial communities and the endophytes of Q. aliena have not been investigated. The differences or the common effects of truffle colonization on microbial communities associated with different host species remain unknown. Hence, we conducted high-throughput sequencing to access the impact of truffle ectomycorrhizal synthesis on microbial communities and to identify the core microbial flora in the rhizosphere soil and the $Q$. aliena roots. In the present study, we also determined the metabolic responses of the host plant ( $Q$. aliena) to the colonization of the $T$. indicum using function prediction tools and metabolomics approaches. To our knowledge, this is the first 
time the metabolomics was used to reveal the metabolisms of truffles in response to truffle ectomycorrhization, with the aims to enhance the insight into the biological and chemical interactions between the host plant and T. indicum and to produce practical guides on the commercial cultivation of truffles sustainably.

\section{MATERIALS AND METHODS}

\section{Ectomycorrhizal Synthesis and Sampling Strategy}

Ectomycorrhizae of Q. aliena with T. indicum were synthesized in a greenhouse in Chengdu, Sichuan, China, according to our previous described methods (Li et al., 2017) with some modifications. Briefly, the $Q$. aliena seeds were first surface sterilized with $30 \% \mathrm{H}_{2} \mathrm{O}_{2}$ for $4 \mathrm{~h}$ and washed with distilled water for three times. Substrate I (consisting of vermiculite, perlite, and water at a ratio of $1: 1: 1, \mathrm{v} / \mathrm{v} / \mathrm{v}$ ) and Substrate II (consisting of peat, vermiculite, organic soil, and water at a ratio of $1: 1: 1: 0.9, \mathrm{v} / \mathrm{v} / \mathrm{v} / \mathrm{v})$ were autoclave sterilized for $90 \mathrm{~min}$ at $121^{\circ} \mathrm{C}$ prior to use. The surface-sterilized seeds were first sown in a plastic container filled with sterilized Substrate I to germinate. A month later, the $Q$. aliena seedlings were transplanted into separate plots filled with $1 \mathrm{~L}$ of sterilized Substrate II. The final $\mathrm{pH}$ of the homogenized substrates was adjusted to 7.5 by adding calcium hydroxide. The spore powder of $T$. indicum was obtained by blending ascocarps, surface sterilized with $75 \%$ alcohol and soaked with sterile water, to incite the spores to be released and to germinate. Ascocarps were collected from a mountain, on which $T$. indicum formed a symbiotic relationship with pine trees. We inoculated $2 \mathrm{~g}$ of the T. indicum spore powder into the substrate of each $Q$. aliena seedling. Six $Q$. aliena seedlings that were not inoculated with the truffle spores served as controls. Each treatment had six biological replicates. All the 12 pots were maintained in the greenhouse under the same conditions. Plants were watered every 3 days. After 5 months, the ectomycorrhizae were successfully obtained in all the six seedlings inoculated with truffle spores; the other six control seedlings were not colonized by truffles, as revealed by morphology analysis (Figure 1). The mycorrhization was checked using a stereomicroscope and the colonization rate was about $49 \%$ according to the method described by Andres-Alpuente et al. (2014). The identification of the $T$. indicum mycorrhizae was checked by ITS-rDNA sequence analyses according to Geng et al. (2009). Q. aliena root tips (approximately $0.5 \mathrm{~g}$ ), mycorrhized with truffle mycelia (ECM) or without (CK), were surface sterilized and preserved at $-80^{\circ} \mathrm{C}$, prior to metabolomics analysis and MiSeq sequencing. The root-surrounding (rhizosphere) soil (about $100 \mathrm{~g}$ ) was also collected and immediately subjected to chemical determination and microbial diversity analysis. The soil surrounding the root tips of Q. aliena mycorrhized with $T$. indicum was assigned to ECM.S. The soil surrounding the roots of the control trees without T. indicum partner was assigned to CK.S in the following text. Four replicates were used for microbiome analysis whereas six for metabolic analysis in order to reduce the error in metabolome detection.

\section{Determination of Soil Properties}

The properties of soil samples surrounding the roots were analyzed according to our previously described method (Li et al., 2016, 2017). Briefly, soil pH was measured by dissolving air-dried soil in distilled water at the ratio of 1:5. Organic matter content was detected using the Tyurin method (Itoh et al., 2013). Total nitrogen was determined by the Kjeldahl method (Itoh et al., 2013). Total phosphorus was measure using molybdenum antimony ascorbic acid spectrophotography. Total potassium was determined by flame photometry. Available nitrogen was quantified using alkali solution diffusion method. Available phosphorus was determined using baking soda leaching - molybdenum antimony colorimetric method. Available potassium was determined by ammonium acetate extraction - flame photometry. Soil magnesium and calcium were measured by inductively coupled plasma optical emission spectroscopy (Optima 2000 DV, PerkinElmer, United States), with yttrium as the internal standard. All the experiments were conducted in triplicates.

\section{DNA Extraction and MiSeq Sequencing}

The ectomycorrhizae or the control roots of Q. aliena were first surface sterilized according to our previous described method (Li et al., 2017). Total genomic DNA of the surface sterilized roots were extracted using cetyltrimethyl ammonium bromide (CTAB) method (Clarke, 2009). The genomic DNA of the rootsurrounding soil was extracted using the Soil DNA Kit (D562501, Omega Bio-tek, Inc., Norcross, GA, United States) following the manufacturer's instructions. DNA quality was monitored on $1 \%$ agarose gels. The DNA per sample was diluted to $1 \mathrm{ng} / \mu \mathrm{L}$ using sterile water. The partial $16 \mathrm{~S}$ rRNA gene (V4 region) was amplified using the universal primers $341 \mathrm{~F}-806 \mathrm{R}$ and the fungal partial ITS gene (ITS1 region) using primers ITS1F - ITS2, with barcodes added as markers to distinguish the individual samples (Huang et al., 2015; Fu et al., 2016). To study the endophytic and soil-borne microbial communities, Illumina's MiSeq sequencing was used. The MiSeq sequencing libraries were constructed according to our previous described methods ( $\mathrm{Li}$ et al., 2017). Libraries were sequenced on an Illumina MiSeq platform and $250 \mathrm{bp}$ paired-end reads were generated (Caporaso et al., 2012).

\section{MiSeq Sequencing Data Analysis}

The paired-end raw reads were first filtered using a series of quality control methods, including removing the barcode and primer sequences, merging overlapped sequences and removing chimera sequences, to obtain high quality data (Haas et al., 2011; Magoc and Salzberg, 2011; Bokulich et al., 2013). Sequence analysis was performed using the Uparse software (Edgar, 2013). The operational taxonomic units (OTUs) were assigned at $\geq 97 \%$ similarity threshold. One representative sequence per OTU was screened for further taxonomic annotation. Bacterial and fungal taxonomic annotation was performed using RDP 3 classifier (Wang et al., 2007), based on the Greengenes database (DeSantis et al., 2006) and the UNITE database (Koljalg et al., 2005), respectively. To minimize the difference in sequencing 


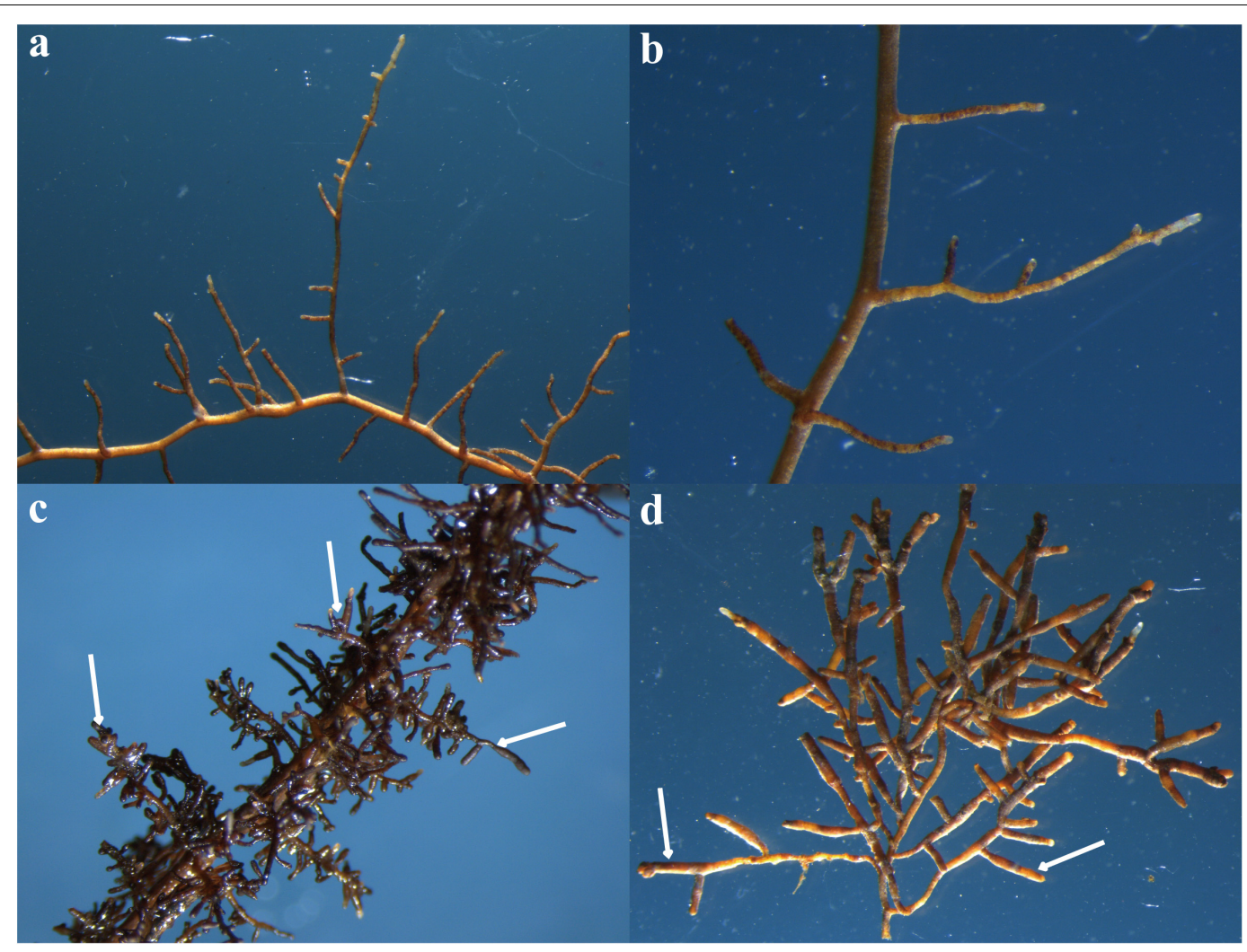

FIGURE 1 | Root tips of Quercus aliena without Tuber indicum $\mathbf{( a , b )}$ or with T. indicum partner $\mathbf{( c , d ) . ~ T h e ~ w h i t e ~ a r r o w s ~ i n d i c a t e ~ t h e ~ i n f l a t e d ~ r o o t ~ t i p s ~ w h i c h ~ a r e ~}$ colonized by T. indicum. These pictures were photographed using routine stereo microscopes (M80, Leica Microsystems, Inc., Buffalo Grove, IL, United States) under different magnification. (a) 10; (b) 20; (c) 13; (d) 16.

effort across samples, the abundance of each OTU per sample was normalized by rarefying the OTUs to the smallest sample library size. Subsequent analyses of alpha diversity and beta diversity were performed based on the normalized OTU data using QIIME Version 1.7.0 (Caporaso et al., 2010). Alpha diversity was applied to analyze the species complexity of each sample with five ecological indices, including observed species, Chaol (Chao, 1984), ACE (Chao and Lee, 1992), Shannon, and Simpson. The metabolic functions of the bacterial communities were predicted using Phylogenetic Investigation of Communities by Reconstruction of Unobserved States (PICRUSt) software (Langille et al., 2013) based on the classification of the microbial metabolic functions present in the KEGG database and the COG database. The fungal functional group (guild) of the OTUs was inferred using FUNGuild v1.0 (Nguyen et al., 2016).

Data of the above microbial community analysis are presented as means \pm standard deviations (SD) of four biological triplicates for each treatment. Statistical analysis was carried out by one-way analysis of variance (ANOVA) using SPSS 19.0. Least significant difference (LSD) was performed to test if the ANOVA result between the treatment groups was significant at $P<0.05$. Spearman correlation coefficient (rho) between soil properties and indicators of bacterial communities were calculated using SPSS 19.0.

\section{Metabolite Extraction}

The frozen plant root tips (100 mg) were ground into fine powders under liquid nitrogen using a high flux organization grinding apparatus (JQ-M4, JIQUN, Co., Ltd., Hebei, China). Metabolite extraction for ultra-high performance liquid chromatography time of flight tandem mass spectrometry (UHPLC-TOF-MS/MS) was carried out following the previously described method (Weckwerth et al., 2004; Rao et al., 2016). Briefly, $1000 \mu \mathrm{L}$ of methanol (pre-cooled at $-20^{\circ} \mathrm{C}$ ) was added to the fine powders, followed by vortex-mixing for $30 \mathrm{~s}$. The mixture was transferred into an ultrasound machine at room temperature for $30 \mathrm{~min}$. Then $750 \mu \mathrm{L}$ of chloroform (pre-cooled at $\left.-20^{\circ} \mathrm{C}\right)$ and $800 \mu \mathrm{L}$ of deionized water $\left(\mathrm{dH}_{2} \mathrm{O}, 4^{\circ} \mathrm{C}\right)$ were added. The mixture was vortex-mixed for $1 \mathrm{~min}$ and centrifuged for $10 \mathrm{~min}(12000 \mathrm{rpm})$. The supernatant was transferred into a new Eppendorf tube and passed through a $0.22 \mu \mathrm{m}$ membrane filter. In order to avoid system errors, all of the samples were injected into the apparatus randomly. We also introduced the quality control (QC) samples to ensure the stability of the system.

\section{Detection of Metabolites by UHPLC-TOF-MS/MS}

Acquity Ultra Performance LC system (Waters, United States) was used in this study and operated according to the instructions. 
Acquity UPLC BEH C18 column $(2.1 \mathrm{~mm} \times 100 \mathrm{~mm}, 1.7 \mathrm{~mm}$, Waters, United States) was maintained at $40^{\circ} \mathrm{C}$. A sample volume of $4 \mu \mathrm{L}$ with the partial loop injection mode was used in all of the experiments. The temperature of the autosampler was kept at $4^{\circ} \mathrm{C}$. Gradient elution of the analytes was carried out with $0.1 \%$ formic acid in water $(\mathrm{A})$ and $0.1 \%$ formic acid in acetonitrile (B) at a flow rate of $0.25 \mathrm{~mL} / \mathrm{min}$. An increasing linear gradient of solvent $B(\mathrm{v} / \mathrm{v})$ was used as follows: $0 \sim 1 \mathrm{~min}$, $2 \% \mathrm{~B} ; 1 \sim 9.5 \mathrm{~min}, 2 \% \sim 50 \% \mathrm{~B} ; 9.5 \sim 14 \mathrm{~min}, 50 \% \sim 98 \% \mathrm{~B}$; 14 15 $\min , 98 \% \mathrm{~B}$; 15 15.5 $\mathrm{min}, 98 \% \sim 2 \% \mathrm{~B} ; 15.5 \sim 17 \mathrm{~min}, 2 \%$. The chromatographic column was kept balanced for 1 min prior to taking the next sample. The leucine enkephalin was used as the lock and spray $\left(0.4 \mathrm{ng} \mathrm{\textrm {L } ^ { - 1 }}, 0.1 \%\right.$ formic acid, $\mathrm{CAN} / \mathrm{H}_{2} \mathrm{O}$ 50/50).

The ESI-MS experiments were executed on the Thermo LTQOrbitrap XL mass spectrometer with the spray voltage of 4.8 and $-4.5 \mathrm{kV}$ in positive and negative modes, respectively. Sheath gas and auxiliary gas were set at 45 and 15 arbitrary units, respectively. The capillary temperature was $325^{\circ} \mathrm{C}$. The voltages of capillary and tube were 35 and $50 \mathrm{~V},-15$ and $-50 \mathrm{~V}$ in positive and negative modes, respectively. The Orbitrap analyzer scanned over a mass range of $\mathrm{m} / \mathrm{z}$ 89-1,000 for full scan at a mass resolution of 60,000. Data dependent acquisition (DDA) MS/MS experiments were performed with CID scan. The normalized collision energy was $30 \mathrm{eV}$. Dynamic exclusion was implemented with a repeat count of 2 and an exclusion duration of $15 \mathrm{~s}$.

\section{Metabolic Profiling Analysis}

Metabolite peaks in the LC-MS/MS data were extracted by Waters Masslynx 4.1 software. Raw MS files were turned into mzXML format by Proteowizard software (v3.0.8789) and sequentially processed by XCMS software running under $\mathrm{R}$ (v3.1.3) for chromatographic matching, metabolic features detection, and aligning all metabolite peaks of the LC-MS data. In the end, all of the peak areas were normalized by the sum and then subjected to statistical analyses.

Multivariate analyses were performed using Soft Independent Modeling of Class Analogy (SIMCA)-P (version 11.0, Umetrics AB, Umeå, Sweden). All variables were UV (Unit Variance) scaled before partial least squares-discriminant analysis (PLS-DA) and principal component analysis (PCA). A loading plot was used to show the contributions of different variables to the samples. The notable different metabolites were screened by the loading plot in PLS-DA and PCA. Subsequently, independent $t$-test was performed to determine significant metabolites between different groups $(P \leq 0.05)$. Hierarchical clustering analysis (HCA) was carried out using $\mathrm{R}$ software (v3.1.3) to group and visualize metabolite profiles. Metabolic pathways were mapped according to pathway topology analysis on Metaboanalyst and KEGG metabolic database ${ }^{1}$.

Pearson correlation coefficient was used to analyze the correlation between the metabolites. Data with $r^{2} \geq 0.49$ and false discovery rate $(F D R) \leq 0.05$ were screened for the final link drawing. Correlation coefficient was calculated by $\mathrm{R}$ language.

\footnotetext{
${ }^{1}$ http://www.kegg.jp/
}

The Cytoscape $3.02^{2}$ was used for metabolic pathway drawing and visualization.

\section{RESULTS}

\section{Prokaryotic Alpha Diversity Indices}

High-throughput sequencing technique was used to detect the differences in microbial diversity in the Q. aliena root tips and the surrounding soil with and without the colonization of T. indicum. The rarefaction curves of the prokaryotic (bacterial and archaeal) and fungal OTUs in different samples are shown in Supplementary Figure S1.

An average of 57,963 reads were obtained per sample after quality control procedures. Altogether, 42 phyla, 165 classes, and 930 genera of bacteria and archaea were classified in all samples. The number of OTUs assigned at the 97\% similarity threshold ranged from 976 to 2067 across samples. The analysis of the estimated richness indices (e.g., observed species, Chaol and ACE) revealed that the ectomycorrhizosphere soil (ECM.S) and the roots without $T$. indicum partners (CK) harbored the highest and the lowest prokaryotic richness, respectively (Table 1). The two diversity indices (e.g., Shannon and Simpson) indicated that prokaryotic diversity was highest in the ectomycorrhizosphere soil (ECM.S) and the rhizosphere soil without T. indicum partner (CK.S) and lowest in the roots without $T$. indicum partners (CK).

\section{Fungal Alpha Diversity Indices}

The rhizosphere soil without T. indicum partner (CK.S) exhibited the highest fungal richness, whereas the root samples with T. indicum partner (ECM) showed the lowest fungal richness (Table 1). The fungal diversity indices (e.g., Shannon and Simpson) were significantly higher in soil (CK.S and ECM.S) than in the roots (CK and ECM), irrespective of $T$. indicum inoculation.

\section{Taxonomic Analyses of Prokaryotic Communities}

At the phylum level, 25 prokaryotic phyla were shared across all the samples. Proteobacteria, Actinobacteria, Bacteroidetes, and Chloroflexi were the dominant bacterial phyla in all samples (Figure 2A). The relative abundance of Actinobacteria and Chloroflexi were significantly higher in ECM and ECM.S samples than the corresponding controls $(P<0.05)$. The archaeal phylum Euryarchaeota was only detected in CK.S, accounting for less than $0.1 \%$ of the prokaryotic community (data not shown).

At the class level, Alphaproteobacteria, Gammaproteobacteria, Actinobacteria, Betaproteobacteria, and Anaerolineae were dominant (Figure 2B). Alphaproteobacteria was more abundant in ECM than in CK, whereas Gammaproteobacteria was more abundant in CK than in ECM $(P<0.05)$. Alphaproteobacteria was more abundant in ECM.S than in CK.S, whereas

\footnotetext{
${ }^{2}$ http://www.cytoscape.org/
} 
TABLE 1 | Community richness and diversity indices of bacteria and fungi in the roots and rhizosphere soil of Quercus aliena with or without Tuber indicum partner.

\begin{tabular}{|c|c|c|c|c|c|}
\hline Sample & CK & ECM & CK.S & ECM.S & \\
\hline \multirow[t]{5}{*}{ Bacterial indices } & Observed species & $1136 \pm 109 c$ & $1722 \pm 56 b$ & $1737 \pm 57 b$ & $1983 \pm 90 a$ \\
\hline & Chao1 & $1027 \pm 249 c$ & $1355 \pm 100 c$ & $1776 \pm 130 b$ & $2276 \pm 107 a$ \\
\hline & ACE & $1081 \pm 266 d$ & $1432 \pm 103 c$ & $1796 \pm 168 b$ & $2346 \pm 128 a$ \\
\hline & Shannon & $5.28 \pm 0.63 c$ & $6.53 \pm 0.28 b$ & $9.17 \pm 0.04 a$ & $9.27 \pm 0.07 a$ \\
\hline & Simpson & $0.84 \pm 0.02 c$ & $0.90 \pm 0.02 b$ & $0.99 \pm 0.00 a$ & $1.00 \pm 0.00 a$ \\
\hline \multirow[t]{5}{*}{ Fungal indices } & Observed species & $126 \pm 24 c$ & $97 \pm 25 c$ & $352 \pm 26 a$ & $256 \pm 34 b$ \\
\hline & Chao1 & $83 \pm 23 c$ & $52 \pm 13 c$ & $298 \pm 27 a$ & $215 \pm 31 b$ \\
\hline & ACE & $83 \pm 22 c$ & $52 \pm 13 c$ & $301 \pm 31 a$ & $215 \pm 31 b$ \\
\hline & Shannon & $1.94 \pm 0.76 b$ & $1.03 \pm 0.14 b$ & $4.34 \pm 0.56 a$ & $3.35 \pm 0.66 a$ \\
\hline & Simpson & $0.60 \pm 0.22 b$ & $0.39 \pm 0.08 c$ & $0.85 \pm 0.09 a$ & $0.78 \pm 0.08 \mathrm{ab}$ \\
\hline
\end{tabular}

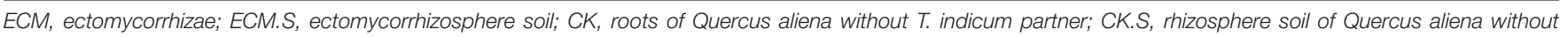

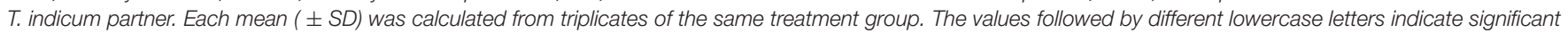
differences $(P<0.05)$ between the treatment groups in a row.

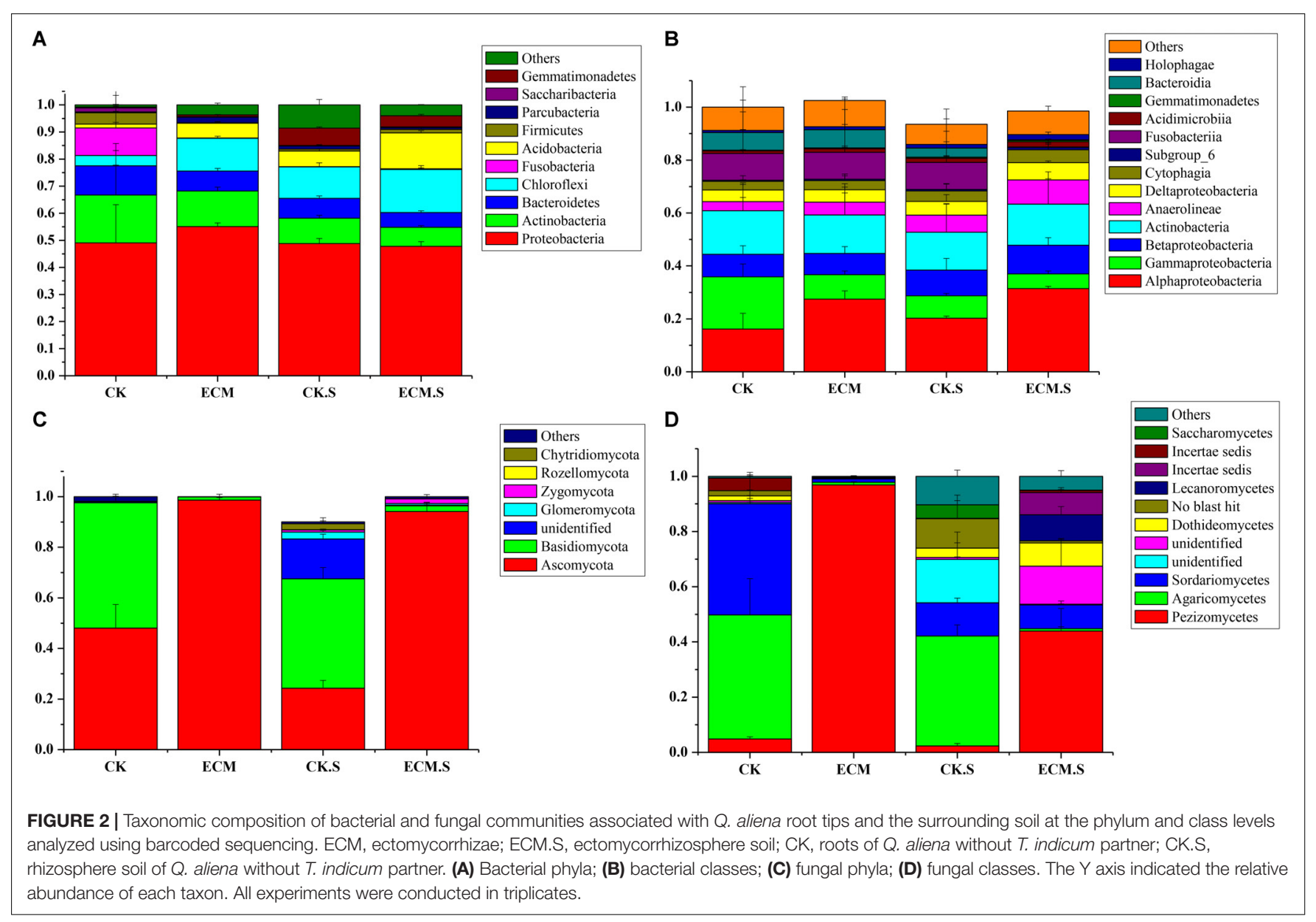

Gammaproteobacteria was more abundant in CK.S than in ECM.S $(P<0.05)$.

At the genus level (Supplementary Figure S2), Actinoplanes (average 2.35\%), Cetobacterium (1.88\%), Pedomicrobium (1.59\%), Devosia (1.49\%), Variibacter (1.40\%), Woodsholea (1.29\%), and Streptomyces (1.25\%) were the dominant genera in all samples (Figure 3A). Out of the 25 most abundant prokaryotic genera, 20 were significantly more abundant in ECM than in CK, such as Aquicella, Arthrobacter, Bacillus, Chlorothrix, Solibacter, Geobacillus, Hyphomicrobium, Humatobacter, Pedomicrobium, Rhodomicrobium, Sandaracinus, Sporecytophaga, Streptomyces, Sulfuritalea, Terrimonas, Turneriella, and Woodsholea $(P<0.05$, Supplementary Figure S3A). The prokaryotic genera such as marine group, Mesorhizobium, Pseudolabrys, Variibacter, and Woodsholea were significantly more abundant in ECM.S than in CK.S $(P<0.05$, Supplementary Figure S3B). 
A

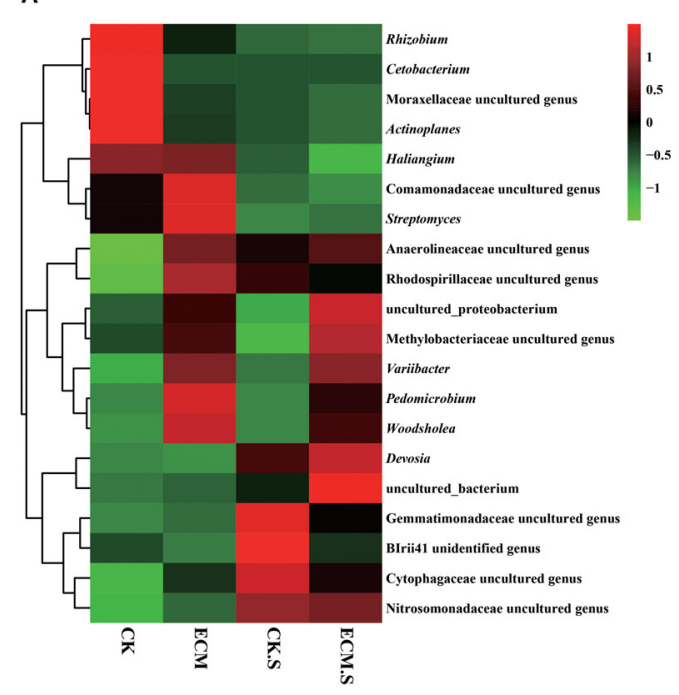

B

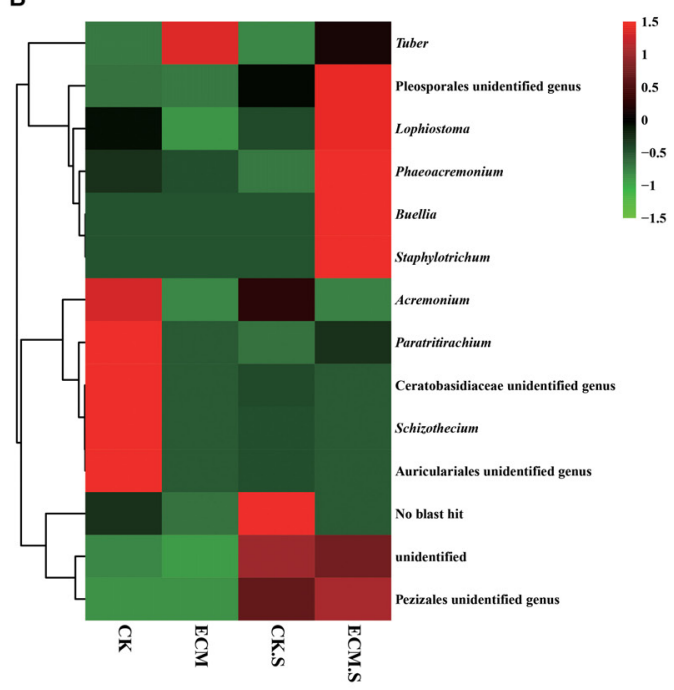

FIGURE 3 | Heat-map analysis of the most abundant (average relative abundance > 0.01) bacterial (A) and fungal (B) genera in Q. aliena roots and the surrounding soil. ECM, ectomycorrhiza; ECM.S, ectomycorrhizosphere soil; CK, roots of Q. aliena without T. indicum partner; CK.S, rhizosphere soil of Q. aliena without T. indicum partner. The relative abundance of the samples at genus level increased with the increase of the color block value.

\section{Taxonomic Analyses of Fungal Communities}

At the phylum level, Ascomycota and Basidiomycota were the two dominant fungal phyla (Figure 2C). The relative abundance of Ascomycota was significantly more abundant in ECM and ECM.S than in the corresponding controls $(P<0.05)$.

At the class level, Pezizomycetes (average 30.59\%), Agaricomycetes (15.70\%), and Sordariomycetes (8.47\%) were the dominant taxa in all the samples (Figure 2D). Pezizomycetes was significantly more abundant in ECM.S than in CK.S $(P<0.05)$. ECM harbored more Pezizomycetes and fewer Agaricomycetes and Sordariomycetes than CK $(P<0.05)$.

Of the 181 genera observed (Supplementary Figure S2), the most abundant genera were Tuber (with average relative abundance of $96.82 \%$ in ECM and $41.65 \%$ in ECM.S), Acremonium, Schizothecium, Buellia, Staphylotrichum, and Phaeoacremonium (Figure 3B). Not surprisingly, Tuber was only detected in the T. indicum-treated samples (ECM.S and ECM). Except Tuber, none of the top 25 genera had higher relative abundance in ECM than in CK. The inoculation of T. indicum decreased the relative abundance of the predominant genera such as Acremonium, Aspergillus, Penicillium, and Claviceps in $Q$. aliena roots $(P<0.05$, Supplementary Figure S3C). In soil, the genera such as Aspergillus, Phaeoacremonium, Pochonia, and Wallemia were significantly more abundant in T. indicum-inoculated samples (ECM.S) than in the controls (CK.S) $(P<0.05$, Supplementary Figure S3D).

\section{Structural Differentiation of Microbial Communities}

The variations of bacterial and fungal communities among the samples were visualized using Non-metric multidimensional scaling (NMDS) analysis (Figure 4). The microbial (both prokaryotic and fungal) community structures were dependent on the sample type (soil versus roots) and $T$. indicum-inoculation dependent. NMDS1 separated the prokaryotic (Figure 4A) and fungal (Figure 4B) communities by the sample type, whereas NMDS2 separated the microbial communities by the T. indicum treatment.

\section{Metabolic Functions of the Bacterial Community}

The metabolic functions of the bacterial community were predicted using PICRUSt software based on the classification of the microbial metabolic functions present against the KEGG database, the COG database, and the Rfam database. Metabolism, genetic information processing, and environmental information processing were the most enriched KEGG pathways in all samples. At the second level, membrane transport, replication and repair, amino acid metabolism, carbohydrate metabolism, and energy metabolism were the most abundant predicted KEGG metabolic functions of the bacterial communities in the roots and the rhizosphere soil of Q. aliena (Figure 5A). The predicted membrane transport function was more abundant, whereas carbohydrate metabolism and replication and repair functions were less abundant in the ectomycorrhizosphere soil than in the T. indicum-free rhizosphere soil $(P<0.05)$. ECM samples contained more abundant amino acid metabolism and less abundant replication and repair functions than the CK samples $(P<0.05)$. At the third level, transporters and $\mathrm{ABC}$ transporters DNA repair and recombination proteins and purine metabolism constituted the most abundant predicted KEGG metabolic functions of the bacterial communities in the roots and the surrounding soil of $Q$. aliena (Figure 5B). The ECM.S samples contained more abundant transporters 

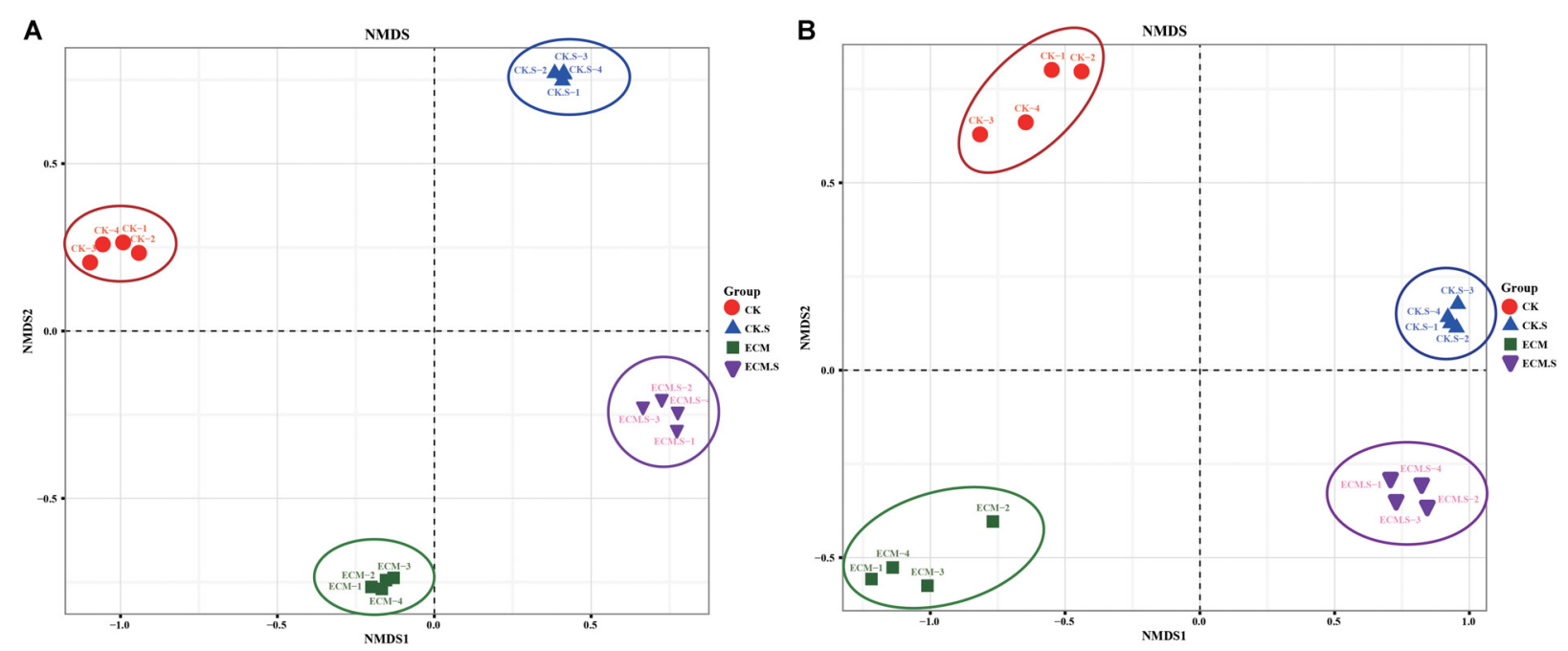

FIGURE 4 | Non-metric multidimensional scaling (NMDS) analysis of bacterial (A) and fungal (B) communities in Q. aliena roots and the surrounding soil and with or without T. indicum partner. ECM, ectomycorrhizae; ECM.S, ectomycorrhizosphere soil; CK, roots of Q. aliena without T. indicum partner; CK.S, rhizosphere soil of Q. aliena without T. indicum partner.
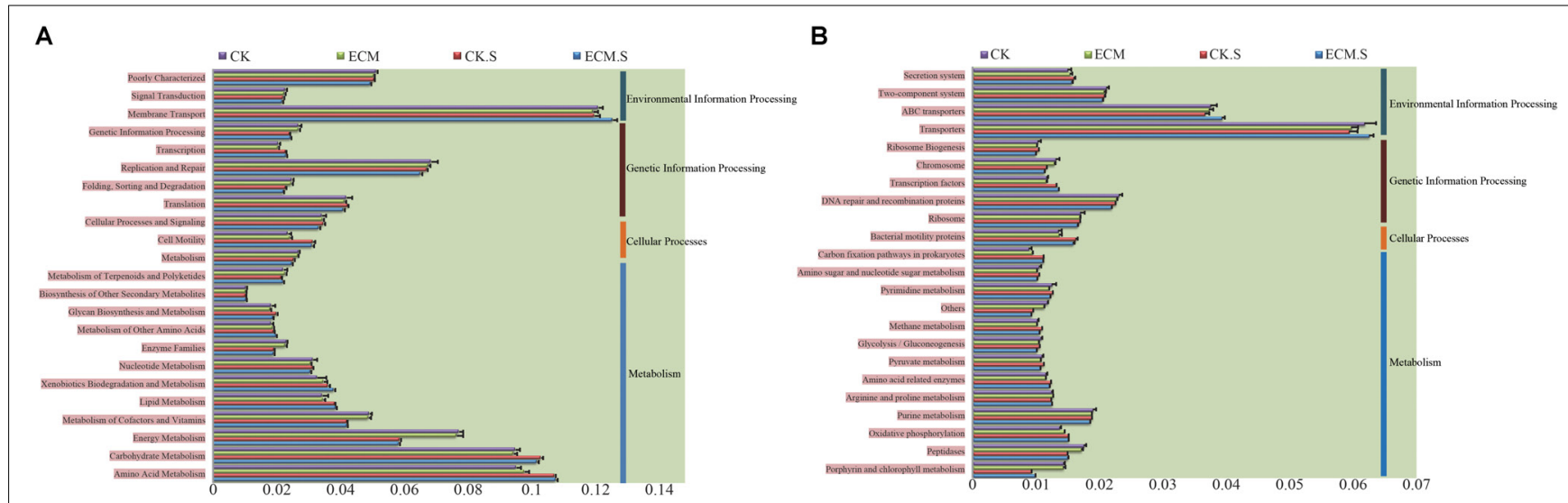

FIGURE 5 | The relative abundance of the putative metabolic functions of the bacterial community in Q. aliena roots and the surrounding soil, predicted using PICRUSt software based on the KEGG database at the second (A) and third (B) classification level. ECM, ectomycorrhizae; ECM.S, ectomycorrhizosphere soil; CK, roots of $Q$. aliena without $T$. indicum partner; CK.S, rhizosphere soil of $Q$. aliena without $T$. indicum partner. The X axis indicates the relative abundance of the metabolic functions of the prokaryotic community. Data of the above metabolic function analysis are presented as mean \pm SD (error bars), calculated from the four biological replicates of each treatment group.

and $\mathrm{ABC}$ transporters and less abundant DNA repair and recombination and purine metabolism functions than the CK.S samples $(P<0.05)$. Transporters, DNA repair and recombination proteins and purine metabolism were less abundant in ECM samples than in the CK samples $(P<0.05)$.

Signal transduction histidine kinase, glycosyltransferase, and response regulators were the most abundant metabolic functions in all the samples predicted based on the COG database (Figure 6A). All of these metabolic functions were more abundant in $Q$. aliena root samples than the surrounding soil samples $(P<0.05)$. RNA polymerase, iron complex receptor and ATP-binding cassette were the most abundant pathways predicted in all the samples based on the KEGG database (Figure 6B). The soil samples contained more abundant RNA polymerase functions and less abundant ATPbinding cassette than the root samples. The ECM sample contained more abundant RNA polymerase and iron complex receptor functions than the $\mathrm{CK}$ samples. ATP-binding cassette was significantly more abundant in ECM.S than in CK.S $(P<0.05)$.

\section{Fungal Functional Group Analysis}

The fungal functional group (guild) of the OTUs was inferred using FUNGuild v1.0. Regarding the trophic mode of the fungal community (Figure 7A), the ECM samples showed higher abundance of symbiotroph and lower abundance of pathogen/saprotroph/symbiotroph 


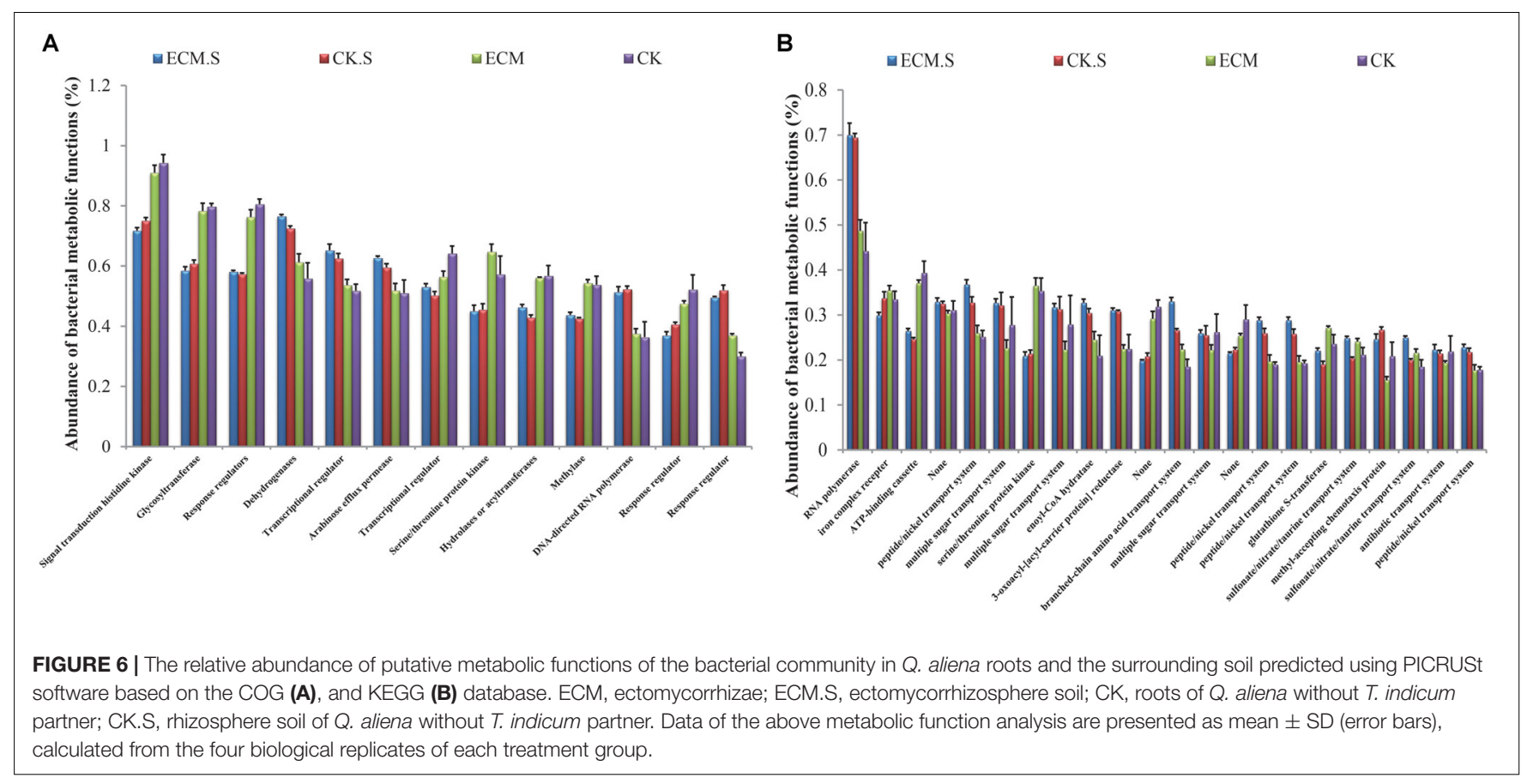

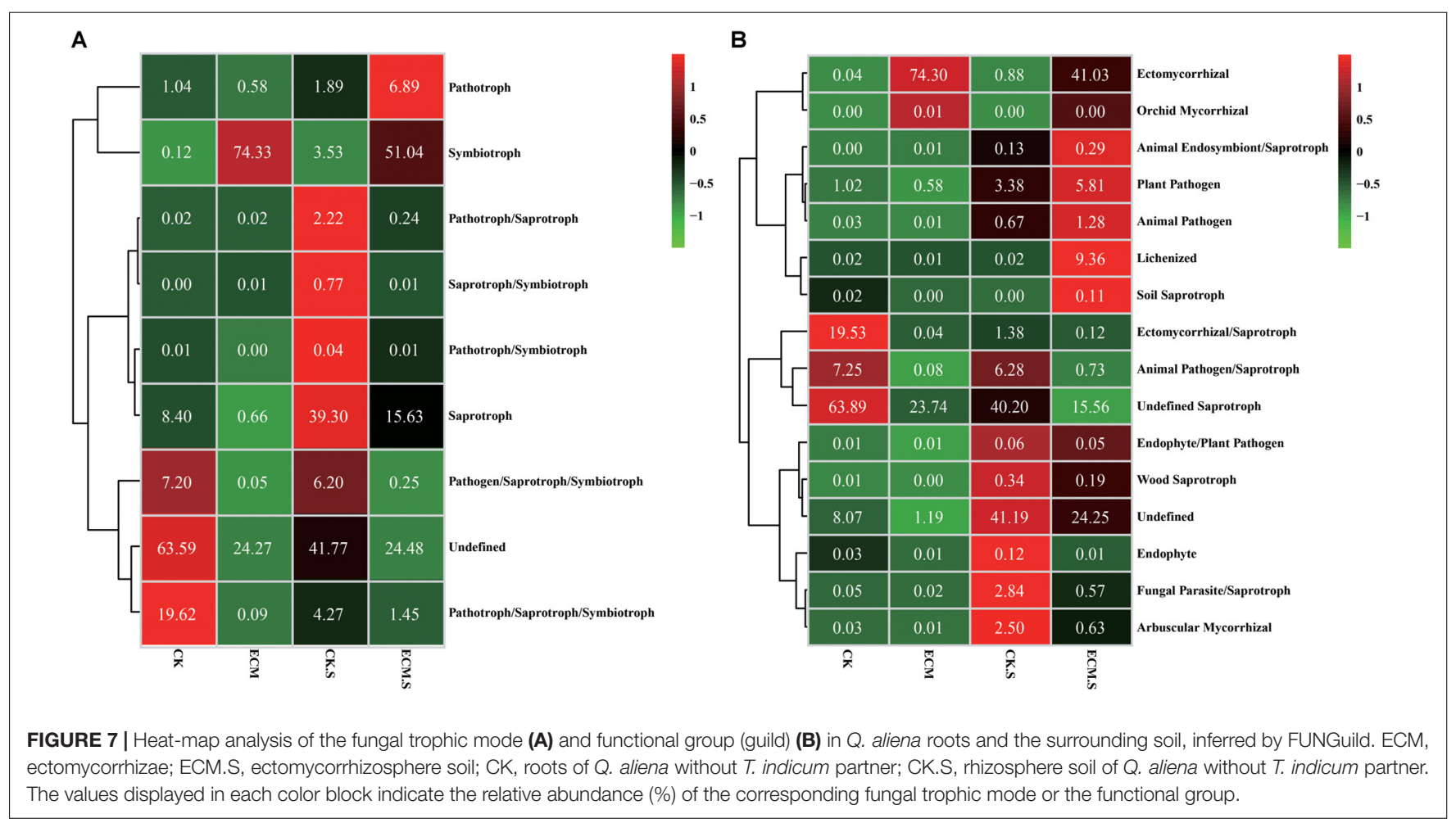

and pathotroph/saprotroph/symbiotroph modes than the CK samples $(P<0.05)$. The ECM.S samples contained more abundant pathotroph and pymbio troph and less abundant pathotroph/saprotroph, saprotroph/ symbiotroph, pathotroph/symbiotroph, saprotroph, pathogen/ saprotroph/symbiotroph, and pathotroph/saprotroph/ symbiotroph modes than the CK.S samples $(P<0.05)$.
Regarding fungal functional group (guild) (Figure 7B), the ECM samples contained more ectomycorrhizal and orchid mycorrhizal functional groups and less ectomycorrhizal/saprotroph, animal pathogen/saprotroph and undefined saprotroph functional groups than the CK samples $(P<0.05)$. The ECM.S samples contained more ectomycorrhizal, animal endosymbiont/saprotroph, plant pathogen, animal 
pathogen, lichenized, and soil saprotroph groups and less wood saprotroph, endophyte, fungal parasite/saprotroph, and arbuscular mycorrhizal groups than the CK.S samples $(P<0.05)$.

\section{Characteristics of Soil Properties and Correlation Analysis}

Most of the soil physicochemical properties detected in this study significantly differed between ECM.S and CK.S (Table 2). The $\mathrm{pH}$ of the ectomycorrhizosphere soil varied from 8.61 to 8.64. The ectomycorrhizosphere soil (ECM.S) contained more organic matter, total nitrogen, available nitrogen, and available magnesium than the control soil (CK.S) $(P<0.05)$. The content of available phosphorus, available potassium, and available calcium was significantly lower in ECM.S than in CK.S $(P<0.05)$. This study revealed significant correlations between the measured soil properties and the microbial indices (including the alpha diversity indices and abundance of the major bacterial phyla) in soil (Supplementary Table S1) and in roots (Supplementary Table S2).

\section{Metabolomic Profiling and Differentially Expressed Metabolites Between Ectomycorrhizae and the Control Roots}

Quercus aliena root tips infected with or without T. indicum were sampled for LC-MS analysis. Orthogonal-partial least squaresdiscriminant analysis (OPLS-DA) clearly divided the 12 samples (including six ECM and six CK samples) into two groups (Figure 8). The first two principal components explained 30.7\% of the overall variance of the metabolite profiles (18.2\% for PC1 and $12.5 \%$ for PC2).

Independent $t$-test was performed to determine the significantly expressed metabolites of ectomycorrhizae (ECM) compared to the $T$. indicum-free control roots $(\mathrm{CK})$. Of the 14704 detected metabolites, 633 metabolites showed significant differential expression patterns between ECM and CK. Fifty-five named metabolites were confirmed using National Institute of Standards and Technology (NIST) and Wiley libraries, including 44 upregulated and 11 downregulated metabolites in ECM compared with those in CK (Figure 9).

The metabolic pathways of the metabolites were analyzed according to the Kyoto Encyclopedia of Genes and Genomes (KEGG) database. The 55 identified metabolites that showed differentially expression patterns between ECM and $\mathrm{CK}$ covered 50 pathways or metabolisms, including the linoleic acid metabolism, citrate cycle (TCA cycle), alanine, aspartate, and glutamate metabolism, flavonoid biosynthesis and butanoate metabolism. Particularly, the Linoleic acid metabolism was significantly enriched in ECM with regard to CK (Supplementary Figure S4).

We then calculated the variations of the differentially expressed metabolites to further reveal the metabolic differentiation in Q. aliena root tips mycorrhized with or without T. indicum partner. These 55 differentially expressed metabolites included 19 organic acids, 9 amines and carbohydrates, 8 flavonoids, and 3 amino acids. The 44 metabolites that were significantly upregulated in ECM were mainly composed of organic acids and carbohydrates, including (R)-malic acid, (R)pantothenic acid, 2-oxoglutaric acid, azelaic acid, caffeic acid, ADP-D-ribose and keto-D-fructose (Supplementary Figure S5). The 11 metabolites that were significantly downregulated in ECM were mainly composed of flavonoids and amino acids, including myricitrin, Quercetin, taurine, and tryptophan.

\section{Metabolite-Metabolite Correlation Analysis}

Person correlation coefficient analysis was used to analyze the metabolite-metabolite interactions among the identified metabolites in $Q$. aliena root tips. There were 729 significant interactions $(P<0.05)$, including 503 positive and 226 negative interactions (Supplementary Figure S6). Notably, organic acids dominated the significant metabolite correlations, followed by carbohydrates.

\section{DISCUSSION}

\section{Truffle Affects the Microbial Diversity in Ectomycorrhizae and Ectomycorrhizosphere Soil}

Because most of the microbes in nature are unculturable, the application of high throughput sequencing facilitates us to gain a comprehensive perspective on ectomycorrhizae associated microbial communities (Zhou et al., 2017). In the present study, the inoculation of $T$. indicum on $Q$. aliena roots significantly increased prokaryotic diversity and richness in both $Q$. aliena roots and the surrounding soil, in contrast with the finding that the ectomycorrhization of $T$. indicum with $P$. armandii reduces the bacterial and fungal diversity in the host roots and the surrounding soil (Li et al., 2017). Zampieri et al. (2016) have also reported that the brûlé reduces the diversity of plant and microbial species. As the environmental condition and the host plant species differ in these studies, one might suggest that truffles have different effects on the associated bacterial communities in varied environments. The diversity and richness of fungi in ectomycorrhizae and ectomycorrhizosphere soil were lower than the corresponding controls, in accordance with the previous study (Li et al., 2017). These results indicate that the effects of the ectomycorrhizal fungus on the diversity of the associated bacteria and fungi are different. Nevertheless, T. indicum changed the microbial community structures in the host roots and the surrounding soil, likely suggesting that the ecotomycorrhization of $T$. indicum plays important ecological roles to affect the associated microbial communities.

\section{Truffle Affects the Dominant Microbial Populations in Ectomycorrhizae and Ectomycorrhizosphere Soil}

Our work revealed that the relative abundance of Alphaproteobacteria was higher in ECM than in CK, in line with previous finding that Alphaproteobacteria were the predominant components of truffle bacterial communities (Li et al., 2017). As Alphaproteobacteria are closely related to the 
TABLE 2 | Properties of the Quercus aliena rhizosphere and the ectomycorrhizosphere soil.

\begin{tabular}{|c|c|c|c|c|c|c|c|c|c|c|}
\hline Sample & $\mathrm{pH}$ & $\begin{array}{c}\text { OM } \\
(g / k g)\end{array}$ & $\begin{array}{c}\text { TN } \\
(\mathrm{g} / \mathrm{kg})\end{array}$ & $\begin{array}{c}\text { TP } \\
(\mathrm{g} / \mathrm{kg})\end{array}$ & $\begin{array}{c}\text { TK } \\
(g / k g)\end{array}$ & $\begin{array}{c}\text { AN } \\
(\mathrm{mg} / \mathrm{kg})\end{array}$ & $\begin{array}{c}\text { AP } \\
(\mathrm{mg} / \mathrm{kg})\end{array}$ & $\begin{array}{c}\text { AK } \\
(\mathrm{mg} / \mathrm{kg})\end{array}$ & $\begin{array}{c}\mathrm{ACa} \\
(\mathrm{cmol} / \mathrm{kg})\end{array}$ & $\begin{array}{c}\mathrm{AMg} \\
(\mathrm{cmol} / \mathrm{kg})\end{array}$ \\
\hline ECM.S & $8.62 \pm 0.02^{*}$ & $29.17 \pm 0.25^{*}$ & $0.94 \pm 0.01^{*}$ & $0.71 \pm 0.00$ & $23.37 \pm 0.43$ & $46.00 \pm 1.73^{*}$ & $14.83 \pm 1.37^{*}$ & $122.33 \pm 0.58^{*}$ & $51.43 \pm 1.06 *$ & $1.40 \pm 0.10^{*}$ \\
\hline CK.S & $8.55 \pm 0.01$ & $20.90 \pm 0.52$ & $0.75 \pm 0.00$ & $0.72 \pm 0.01$ & $22.69 \pm 0.55$ & $28.00 \pm 1.73$ & $25.23 \pm 0.80$ & $642.00 \pm 3.00$ & $58.33 \pm 1.51$ & $0.90 \pm 0.10$ \\
\hline
\end{tabular}

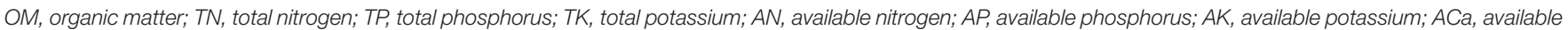

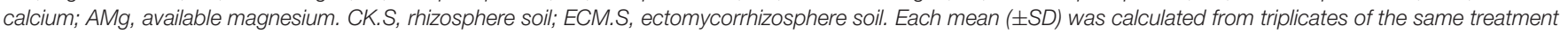
group. *Indicates significant differences $(P<0.05)$ between samples.

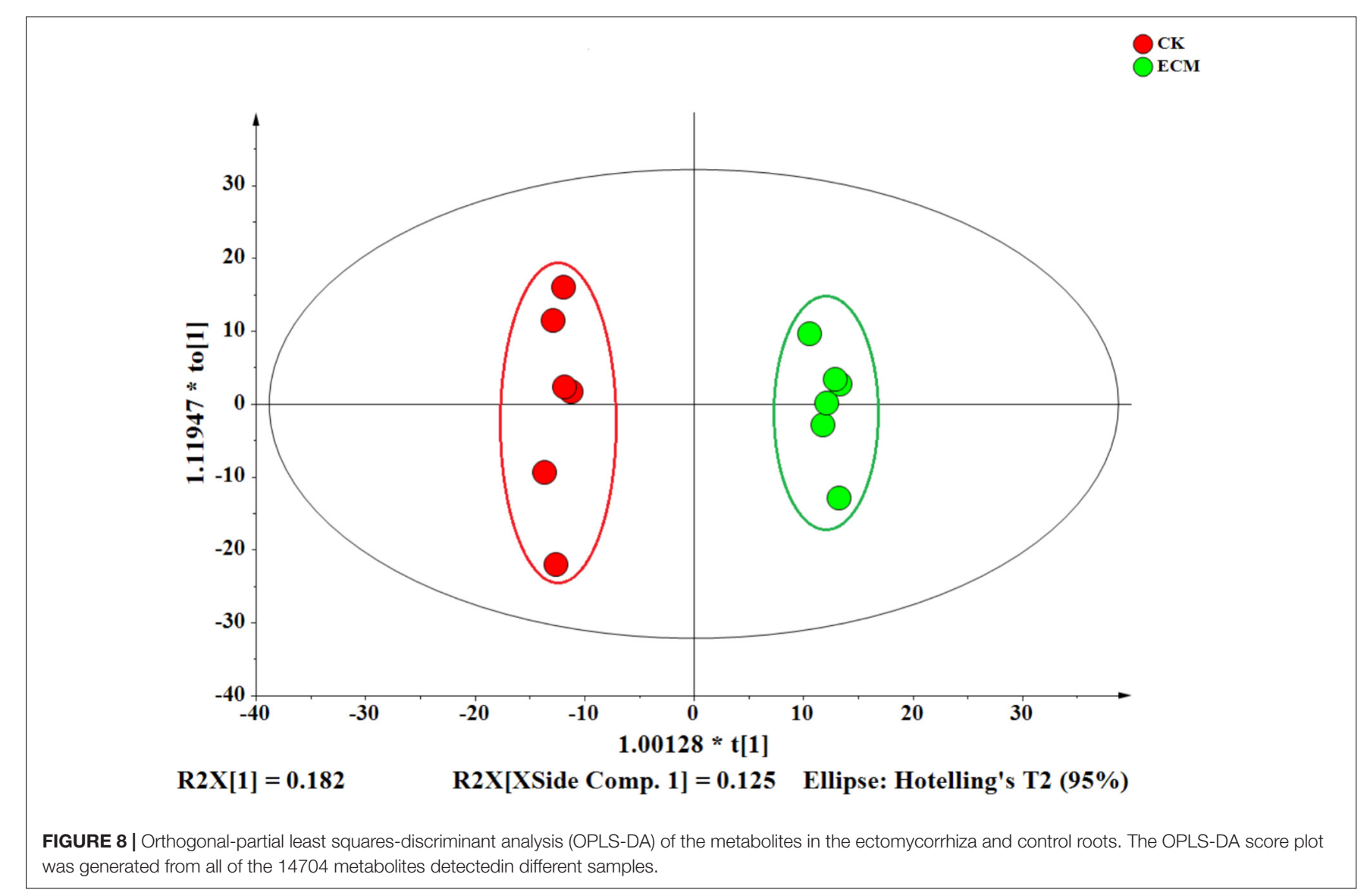

presence of truffle mycelia, they may play an important role in the growth or ectomycorrhizal synthesis of truffles. In the present study, the bacterial genera Pedomicrobium, Variibacter, Woodsholea, and Devosia were detected more abundant in ECM or ECM.S compared with corresponding controls; the fungal genera, Aspergillus, Phaeoacremonium, Pochonia, and Wallemia were found significantly more abundant in ECM.S compared with CK.S. Previous studies have demonstrated that T. melanosporum ascocarps can selected specific bacterial communities from the surrounding soil to contribute to the development, maturation and even aroma of the black truffle (Vahdatzadeh et al., 2015; Deveau et al., 2016). This study, together with our previous research (Li et al., 2017), could further uncover that the truffle $T$. indicum could shape the microbial communities by selecting specific microbial groups in the surrounding environment. Interestingly, we found that truffle-colonization reduced the diversity and abundance of some fungal genera, such as Acremonium, Aspergillus, Penicillium, and Claviceps, surrounding the host tree. This finding is consistent with the results of previous studies that ectomycorrhizal fungi can enhance the resistance of host plants to pathogenic fungi by reducing the number of infected pathogenic microbial populations to plants (Jung et al., 2012; Yanan et al., 2015).

In the present study, the dominant bacterial and fungal genera (except Tuber) detected in the ectomycorrhizosphere soil and ectomycorrhizae were different from those revealed in the ectomycorrhizosphere soil and ectomycorrhizae of $P$. armandii mycorrhized by T. indicum (Li et al., 2017). The differentiation in the microbial communities is most likely caused by different host plants that provide different rhizosphere and endosphere niches (Beckers et al., 2017). The dominance of Tuber in the T. indicumtreated samples is not surprising, as the truffle mycelia has already dominated the microbial communities of ectomycorrhizosphere 


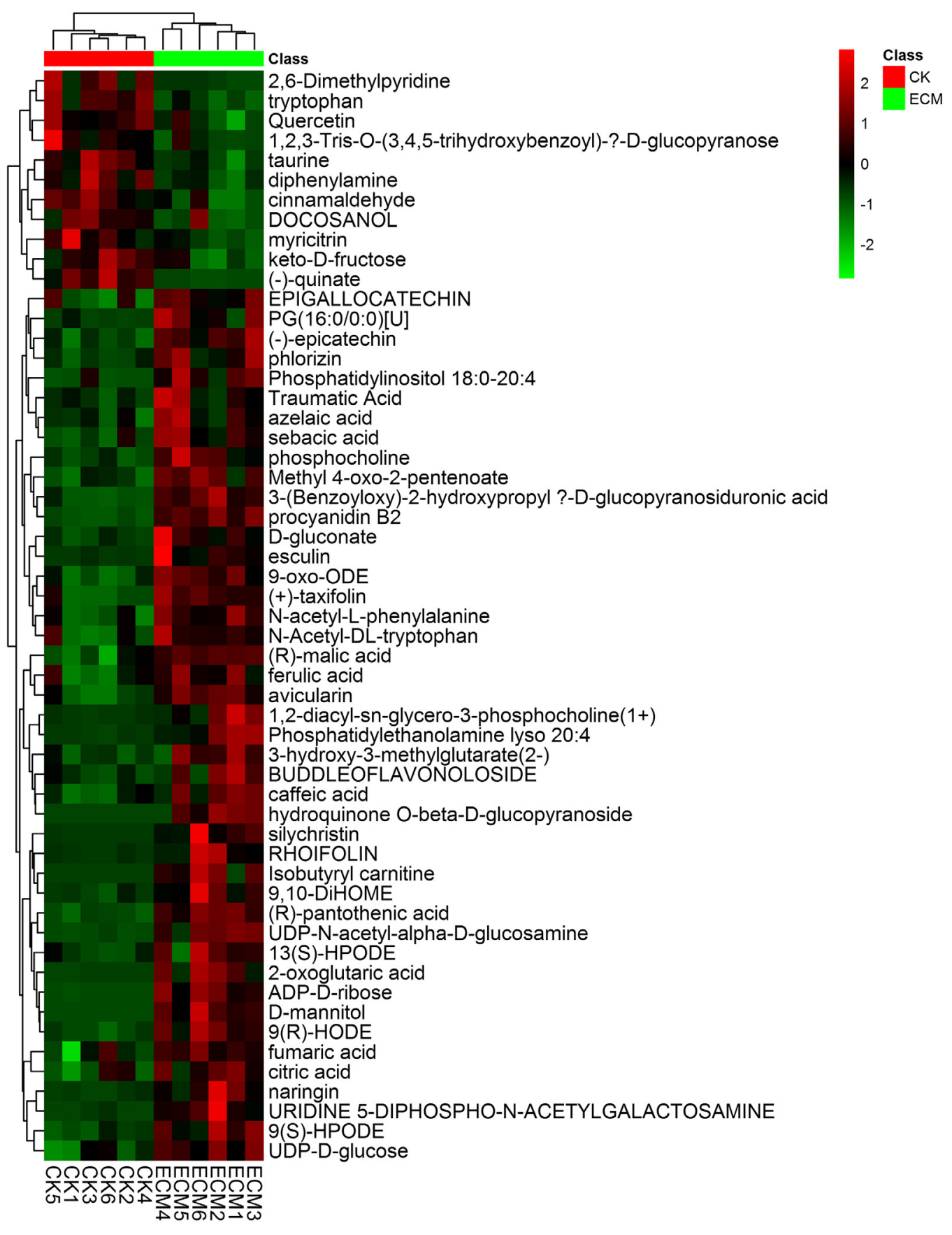

FIGURE 9 | Heat-map analysis of the 55 identified metabolites that differentially expressed between the ectomycorrhizae and the control roots. ECM, ectomycorrhizae (Q. aliena in association with $T$. indicum); CK, roots of $Q$. aliena without $T$. indicum partner.

soil and ectomycorrhizae from the early stage of ectomycorrhizal synthesis (Li et al., 2017).

\section{Microbial Putative Metabolic Functions Are Altered by the Presence of Truffle}

Based on the metabolic functions prediction against KEGG database, membrane transport (particularly transporters and $\mathrm{ABC}$ transporters) and amino acid metabolism were increased in prokaryotic communities of the surrounding soil and roots associated with $T$. indicum, with regard to the corresponding T. indicum-free controls. Transporters and $\mathrm{ABC}$ transporter proteins are all predicted to have an important role in the mycorrhizal symbiosis (Kovalchuk et al., 2015; MacLean et al., 2017; Tian et al., 2017). Our finding might therefore suggest that the activities of ectomycorrhizosphere bacteria are beneficial to mycorrhizal synthesis. Carbohydrate metabolism and replication 
and repair (particularly DNA repair and recombination proteins) were decreased in prokaryotic communities of the host roots and the surrounding soil in the presence of $T$. indicum. Microorganisms need to preserve genetic information to prevent the detrimental effects produced by DNA replication and the repair of damage induced by exogenous factors (Zlotorynski, 2016; Chalissery et al., 2017). Hence, this result possibly indicated that the growth of $T$. indicum could enhance the resistance of the associated bacteria to environmental stresses and thereby create an optimum environment for bacterial metabolic activities. The putative metabolic functions analysis further indicated that the colonization of truffles led to differentiation in metabolic functions of the prokaryotic community associated with the host plant. The putative metabolic functions of the microbial communities were also differentiated between roots and the surrounding soil. Based on the COG database, the dominant metabolic functions, signal transduction histidine kinase, glycosyltransferase and response regulators were more abundant in root samples than the soil samples, reflecting that the differentiation of niches could also lead to the variations of metabolic functions of the prokaryotic communities.

It is not surprising that the root and soil samples showed higher abundance of symbiotroph mode and lower abundance of Saprotroph mode in the presence of $T$. indicum, based on fungal trophic mode analysis. Regarding fungal functional group (guild), arbuscular mycorrhizal groups were less abundant in the ectomycorrhizosphere soil than in the $T$. indicum-free rhizosphere soil. The result might indicate that the growth of arbuscular mycorrhizal fungi in the ectomycorrhizosphere soil was inhibited by the presence of $T$. indicum during the early symbiotic stage. Interestingly, the orchid mycorrhizal group was found more abundant in the ectomycorrhizae than in the control roots. However, the function of the orchid mycorrhizal fungal group on the growth and ectomycorrhizal synthesis of truffle is not yet known (Leonardi et al., 2013).

\section{Variations in Ectomycorrhizosphere and Rhizosphere Soil Properties}

In this study, the measured soil physicochemical properties, such as the $\mathrm{pH}$, organic matter, total nitrogen, available nitrogen, available magnesium, available phosphorus, available potassium, and available calcium, significantly differed between the ectomycorrhizosphere soil and the T. indicum-free rhizosphere soil. This finding indicates that the ectomycorrhization has a feedback effect (modification) on soil properties, consistent with the previous studies ( $\mathrm{Li}$ et al., 2017; Yang et al., 2017). The soil properties, such as the soil $\mathrm{pH}$, carbonate content and available calcium content, play an important role in the production of truffles (Valverde-Asenjo et al., 2009; Garcia-Barreda et al., 2017). Therefore, the changes in soil properties may affect the growth and mycorrhizal synthesis of $T$. indicum. The ectomycorrhizosphere soil in the present study was alkalescent, which is considered suitable for the cultivation of different varieties of truffles (Garcia-Montero et al., 2008; Salerni et al., 2014). However, the ectomycorrhizosphere soil (T. indicum mycorrhized with $P$. armandii) was found slightly acidic in our previous study (Li et al., 2017). The contrasting results indicated that host plant species or the host-truffle interaction can affect the $\mathrm{pH}$ of the ectomycorrhizosphere soil. Moreover, some soil physical and chemical properties were significantly correlated with the estimated microbial diversity indices and the relative abundance of the dominant microbial populations in both ectomycorrhizae and the ectomycorrhizosphere soil. This study further confirms the existence of an interactive network among the truffle, the host plant, soil properties and the associated microbial communities as revealed by $\mathrm{Li}$ et al. (2017).

\section{Changes of Metabolic Profiles in Ectomycorrhiza and Control Roots}

Orthogonal-partial least squares-discriminant analysis analysis revealed that the colonization of $T$. indicum signficantly changed the metabolic profiles in roots. We identified 55 named metabolites that showed significant differential expression patterns between the ectomycorrhizae and Q. aliena roots. The majority $(88 \%)$ of them were significantly upregulated in the presence of $T$. indicum. These upregulated metabolites are mainly composed of organic acids and carbohydrates, such as (R)-malic acid, (R)-pantothenic acid, 2-oxoglutaric acid, azelaic acid, caffeic acid, ADP-D-ribose, and keto-Dfructose. As the main carbon sources transferred to arbuscular mycorrhizal fungi from host plants (Luginbuehl et al., 2017), organic acids were also found more abundant in the AM (Mechri et al., 2014). Mycorrhizal fungi benefit from the host plants with carbohydrates supply (Doidy et al., 2012; Ait Lahmidi et al., 2016). Therefore, our findings suggest that organic acids and carbohydrates are the two most important metabolites (carbon and energy sources) transferred between the ectomycorrhizal fungi $T$. indicum and the host plant to sustain the metabolic activities and functions in the truffle ectomycorrhization system.

In our study, the colonization of $T$. indicum decreased the content of flavonoids and amino acids (including myricitrin, quercetin, taurine, and tryptophan) detected in the host roots. Flavonoids, consisting of a group of secondary metabolites derived from the phenylpropanoid pathway, are involved in the process of regulation of arbuscular mycorrhizal colonization in the host plant roots; however, the root endosymbioses are highly complex, which is not only associated to flavonoids, but also to AM fungal genus or even species (Scervino et al., 2005; Abdel-Lateif et al., 2012). The metabolic components detected in the truffle ectomycorrhization system were highly correlated with each other. Notably, organic acids dominated the significant metabolite-metabolite interactions, followed by carbohydrates, indicating their great importance in the metabolic functioning and transmission in the truffle ectomycorrhization system. In spite of the importance of EM associations for plant vitality, previous studied failed to provide information on the molecular and physiological mechanisms of ectomycorrhizal synthesis (Mucha et al., 2014; Shah et al., 2016). 
The ectomycorrhizal synthesis is crucial for efficient cultivation of truffles (Iotti et al., 2016; Marozzi et al., 2017). In the field, a variety of factors have been found to affect the microbial communities associated with truffle ectomycorrhizae, such as the host species, the age of the plantation, the surrounding environment and the management practices (Leonardi et al., 2013; Fu et al., 2016). Different experimental conditions and methods can also induce dynamic changes in microbial community structure in time and space (Benucci and Bonito, 2016). In this study, a controlled artificial ectomycorrhizal synthesis system was established with T. indicum and Q. aliena to systematically test the influence of ectomycorrhizal synthesis on microbial communities in ectomycorrhizae and the surrounding soil, as well as on the metabolic profiling of ectomycorrhizae during the symbiotic process. In conclusion, this study illustrates an interactive network constituted by $T$. indiccum, Q. aliena, soil and the associated microbial communities and reveals the influence of truffle colonization on the differentiation of metabolic components of ectomycorrhiza, providing insights to understand the ecological effect of truffles.

\section{REFERENCES}

Abdel-Lateif, K., Bogusz, D., and Hocher, V. (2012). The role of flavonoids in the establishment of plant roots endosymbioses with arbuscular mycorrhiza fungi, rhizobia and Frankia bacteria. Plant Signal. Behav. 7, 636-641. doi: 10.4161/psb. 20039

Ait Lahmidi, N., Courty, P. E., Brule, D., Chatagnier, O., Arnould, C., Doidy, J., et al. (2016). Sugar exchanges in arbuscular mycorrhiza: RiMST5 and RiMST6, two novel Rhizophagus irregularis monosaccharide transporters, are involved in both sugar uptake from the soil and from the plant partner. Plant Physiol. Biochem. 107, 354-363. doi: 10.1016/j.plaphy.2016.06.023

Allen, M. F., Swenson, W., Querejeta, J. I., Egerton-Warburton, L. M., and Treseder, K. K. (2003). Ecology of mycorrhizae: a conceptual framework for complex interactions among plants and fungi. Annu. Rev. Phytopathol. 41, 271-303. doi: 10.1146/annurev.phyto.41.052002.095518

Alonso Ponce, R., Agreda, T., Agueda, B., Aldea, J., Martinez-Pena, F., and Modrego, M. P. (2014). Soil physical properties influence "black truffle" fructification in plantations. Mycorrhiza 24(Suppl. 1), S55-S64. doi: 10.1007/ s00572-014-0558-7

Alvarez-Lafuente, A., Benito-Matias, L. F., Penuelas-Rubira, J. L., and Suz, L. M. (2018). Multi-cropping edible truffles and sweet chestnuts: production of high-quality Castanea sativa seedlings inoculated with Tuber aestivum, its ecotype T. uncinatum, T. brumale, and T. macrosporum. Mycorrhiza 28, 29-38. doi: 10.1007/s00572-017-0805-9

Andres-Alpuente, A., Sanchez, S., Martin, M., Aguirre, A. J., and Barriuso, J. J. (2014). Comparative analysis of different methods for evaluating quality of Quercus ilex seedlings inoculated with Tuber melanosporum. Mycorrhiza 24(Suppl. 1), S29-S37. doi: 10.1007/s00572-014-0563-x

Beckers, B., Op, De Beeck, M., Weyens, N., Boerjan, W., and Vangronsveld, J. (2017). Structural variability and niche differentiation in the rhizosphere and endosphere bacterial microbiome of field-grown poplar trees. Microbiome 5:25. doi: 10.1186/s40168-017-0241-2

Benucci, G. M. N., and Bonito, G. M. (2016). The truffle microbiome: species and geography effects on bacteria associated with fruiting bodies of hypogeous pezizales. Microb. Ecol. 72, 4-8. doi: 10.1007/s00248-016-0755-3

Bokulich, N. A., Subramanian, S., Faith, J. J., Gevers, D., Gordon, J. I., Knight, R., et al. (2013). Quality-filtering vastly improves diversity estimates from Illumina amplicon sequencing. Nat. Methods 10, 57-59. doi: 10.1038/nmeth.2276

Caporaso, J. G., Kuczynski, J., Stombaugh, J., Bittinger, K., Bushman, F. D., Costello, E. K., et al. (2010). QIIME allows analysis of high-throughput community sequencing data. Nat. Methods 7, 335-336. doi: 10.1038/nmeth. f.303

\section{AUTHOR CONTRIBUTIONS}

$\mathrm{QL}, \mathrm{WP}$, and XL conceived and designed the experiments. QL, LY, JZ, BZ, and XZ performed the experiments. QL, LJY, and $\mathrm{XL}$ wrote and revised the paper. All authors approved the final version of the manuscript.

\section{FUNDING}

This work was supported by the Science and Technology Support Project in Sichuan Province (Grant No. 2016NYZ0040), as well as the Sichuan Mushroom Innovation Team.

\section{SUPPLEMENTARY MATERIAL}

The Supplementary Material for this article can be found online at: https://www.frontiersin.org/articles/10.3389/fmicb. 2018.02202/full\#supplementary-material

Caporaso, J. G., Lauber, C. L., Walters, W. A., Berg-Lyons, D., Huntley, J., Fierer, N., et al. (2012). Ultra-high-throughput microbial community analysis on the Illumina HiSeq and MiSeq platforms. ISME J. 6, 1621-1624. doi: 10.1038/ismej. 2012.8

Chalissery, J., Jalal, D., Al-Natour, Z., and Hassan, A. H. (2017). Repair of oxidative DNA Damage in Saccharomyces cerevisiae. DNA Repair (Amst.) 51, 2-13. doi: 10.1016/j.dnarep.2016.12.010

Chao, A. (1984). Non-parametric estimation of the number of classes in a population. Scand. J. Statist. 11, 265-270.

Chao, A., and Lee, S. M. (1992). Estimating the number of classes via sample coverage. J. Am. Statist. Assoc. 87, 210-217. doi: 10.1080/01621459.1992. 10475194

Chen, J., Guo, S. X., and Liu, P. G. (2011). Species recognition and cryptic species in the Tuber indicum complex. PLoS One 6:e14625. doi: 10.1371/journal.pone. 0014625

Chen, J., Zhang, H., Zhang, X., and Tang, M. (2017). Arbuscular mycorrhizal symbiosis alleviates salt stress in black locust through improved photosynthesis, water status, and $\mathrm{K}(+) / \mathrm{Na}(+)$ homeostasis. Front. Plant. Sci. 8:1739. doi: $10.3389 /$ fpls.2017.01739

Clarke, J. D. (2009). Cetyltrimethyl ammonium bromide (CTAB) DNA miniprep for plant DNA isolation. Cold Spring Harb. Protoc. 2009:pdb.prot5177.

De Miguel, A. M., Agueda, B., Sanchez, S., and Parlade, J. (2014). Ectomycorrhizal fungus diversity and community structure with natural and cultivated truffle hosts: applying lessons learned to future truffle culture. Mycorrhiza 24(Suppl. 1), S5-S18. doi: 10.1007/s00572-013-0554-3

de Vries, R. P., Benoit, I., Doehlemann, G., Kobayashi, T., Magnuson, J. K., Panisko, E. A., et al. (2011). Post-genomic approaches to understanding interactions between fungi and their environment. IMA Fungus 2, 81-86. doi: 10.5598/ imafungus.2011.02.01.11

DeSantis, T. Z., Hugenholtz, P., Larsen, N., Rojas, M., Brodie, E. L., Keller, K., et al. (2006). Greengenes, a chimera-checked 16S rRNA gene database and workbench compatible with ARB. Appl. Environ. Microbiol. 72, 5069-5072. doi: 10.1128/AEM.03006-05

Deveau, A., Antony-Babu, S., Le Tacon, F., Robin, C., Frey-Klett, P., and Uroz, S. (2016). Temporal changes of bacterial communities in the Tuber melanosporum ectomycorrhizosphere during ascocarp development. Mycorrhiza 26, 389-399. doi: 10.1007/s00572-015-0679-7

Doidy, J., Grace, E., Kuhn, C., Simon-Plas, F., Casieri, L., and Wipf, D. (2012). Sugar transporters in plants and in their interactions with fungi. Trends Plant Sci. 17, 413-422. doi: 10.1016/j.tplants.2012.03.009

Edgar, R. C. (2013). UPARSE: highly accurate OTU sequences from microbial amplicon reads. Nat. Methods 10, 996-998. doi: 10.1038/nmeth.2604 
Franklin, O., Nasholm, T., Hogberg, P., and Hogberg, M. N. (2014). Forests trapped in nitrogen limitation-an ecological market perspective on ectomycorrhizal symbiosis. New Phytol. 203, 657-666. doi: 10.1111/nph.12840

Fu, Y., Li, X., Li, Q., Wu, H., Xiong, C., Geng, Q., et al. (2016). Soil microbial communities of three major Chinese truffles in southwest China. Can. J. Microbiol. doi: 10.1139/cjm-2016-0139 [Epub ahead of print].

Garcia-Barreda, S., Molina-Grau, S., Forcadell, R., Sanchez, S., and Reyna, S. (2017). Long-term soil alteration in historical charcoal hearths affects Tuber melanosporum mycorrhizal development and environmental conditions for fruiting. Mycorrhiza 27, 603-609. doi: 10.1007/s00572-017-0773-0

Garcia-Barreda, S., and Reyna, S. (2012). Below-ground ectomycorrhizal community in natural Tuber melanosporum truffle grounds and dynamics after canopy opening. Mycorrhiza 22, 361-369. doi: 10.1007/s00572-011-0410-2

Garcia-Montero, L. G., Di Massimo, G., Manjon, J. L., and Garcia-Abril, A. (2008). New data on ectomycorrhizae and soils of the Chinese truffles Tuber pseudoexcavatum and Tuber indicum, and their impact on truffle cultivation. Mycorrhiza 19, 7-14. doi: 10.1007/s00572-008-0198-x

Geng, L. Y., Wang, X. H., Yu, F. Q., Deng, X. J., Tian, X. F., Shi, X. F., et al. (2009). Mycorrhizal synthesis of Tuber indicum with two indigenous hosts, Castanea mollissima and Pinus armandii. Mycorrhiza 19, 461-467. doi: 10.1007/s00572009-0247-0

Haas, B. J., Gevers, D., Earl, A. M., Feldgarden, M., Ward, D. V., Giannoukos, G., et al. (2011). Chimeric 16S rRNA sequence formation and detection in Sanger and 454-pyrosequenced PCR amplicons. Genome Res. 21, 494-504. doi: 10.1101/gr.112730.110

Huang, X., Liu, L., Wen, T., Zhu, R., Zhang, J., and Cai, Z. (2015). Illumina MiSeq investigations on the changes of microbial community in the Fusarium oxysporum f.sp. cubense infected soil during and after reductive soil disinfestation. Microbiol. Res. 181, 33-42. doi: 10.1016/j.micres.2015. 08.004

Iotti, M., Piattoni, F., Leonardi, P., Hall, I. R., and Zambonelli, A. (2016). First evidence for truffle production from plants inoculated with mycelial pure cultures. Mycorrhiza 26, 793-798. doi: 10.1007/s00572-016-0703-6

Itoh, N., Sato, A., Yamazaki, T., Numata, M., and Takatsu, A. (2013). Determination of the carbon, hydrogen and nitrogen contents of alanine and their uncertainties using the certified reference material L-alanine (NMIJ CRM 6011-a). Anal. Sci. 29, 1209-1212. doi: 10.2116/analsci.29.1209

Jung, S. C., Martinez-Medina, A., Lopez-Raez, J. A., and Pozo, M. J. (2012). Mycorrhiza-induced resistance and priming of plant defenses. J. Chem. Ecol. 38, 651-664. doi: 10.1007/s10886-012-0134-6

Koljalg, U., Larsson, K. H., Abarenkov, K., Nilsson, R. H., Alexander, I. J., Eberhardt, U., et al. (2005). UNITE: a database providing web-based methods for the molecular identification of ectomycorrhizal fungi. New Phytol. 166, 1063-1068. doi: 10.1111/j.1469-8137.2005.01376.x

Kovalchuk, A., Kohler, A., Martin, F., and Asiegbu, F. O. (2015). Diversity and evolution of $\mathrm{ABC}$ proteins in mycorrhiza-forming fungi. BMC Evol. Biol. 15:249. doi: 10.1186/s12862-015-0526-7

Langille, M. G., Zaneveld, J., Caporaso, J. G., Mcdonald, D., Knights, D., Reyes, J. A., et al. (2013). Predictive functional profiling of microbial communities using 16S rRNA marker gene sequences. Nat. Biotechnol. 31, 814-821. doi: $10.1038 /$ nbt.2676

Laparre, J., Malbreil, M., Letisse, F., Portais, J. C., Roux, C., Becard, G., et al. (2014). Combining metabolomics and gene expression analysis reveals that propionyland butyryl-carnitines are involved in late stages of arbuscular mycorrhizal symbiosis. Mol. Plant 7, 554-566. doi: 10.1093/mp/sst136

Larsen, P. E., Sreedasyam, A., Trivedi, G., Podila, G. K., Cseke, L. J., and Collart, F. R. (2011). Using next generation transcriptome sequencing to predict an ectomycorrhizal metabolome. BMC Syst. Biol. 5:70. doi: 10.1186/17520509-5-70

Leonardi, M., Iotti, M., Oddis, M., Lalli, G., Pacioni, G., Leonardi, P., et al. (2013). Assessment of ectomycorrhizal fungal communities in the natural habitats of Tuber magnatum (Ascomycota, Pezizales). Mycorrhiza 23, 349-358. doi: 10.1007/s00572-012-0474-7

Li, H., Smith, S. E., Holloway, R. E., Zhu, Y., and Smith, F. A. (2006). Arbuscular mycorrhizal fungi contribute to phosphorus uptake by wheat grown in a phosphorus-fixing soil even in the absence of positive growth responses. New Phytol. 172, 536-543. doi: 10.1111/j.1469-8137.2006.01846.x
Li, Q., Li, X., Chen, C., Li, S., Huang, W., Xiong, C., et al. (2016). Analysis of bacterial diversity and communities associated with tricholoma matsutake fruiting bodies by barcoded pyrosequencing in sichuan province, Southwest China. J. Microbiol. Biotechnol. 26, 89-98. doi: 10.4014/jmb.1505.05008

Li, Q., Zhao, J., Xiong, C., Li, X., Chen, Z., Li, P., et al. (2017). Tuber indicum shapes the microbial communities of ectomycorhizosphere soil and ectomycorrhizae of an indigenous tree (Pinus armandii). PLoS One 12:e0175720. doi: 10.1371/ journal.pone. 0175720

Liese, R., Lubbe, T., Albers, N. W., and Meier, I. C. (2018). The mycorrhizal type governs root exudation and nitrogen uptake of temperate tree species. Tree Physiol. 38, 83-95. doi: 10.1093/treephys/tpx131

Luginbuehl, L. H., Menard, G. N., Kurup, S., Van Erp, H., Radhakrishnan, G. V., Breakspear, A., et al. (2017). Fatty acids in arbuscular mycorrhizal fungi are synthesized by the host plant. Science 356, 1175-1178. doi: 10.1126/science. aan0081

Luo, Z. B., Janz, D., Jiang, X., Gobel, C., Wildhagen, H., Tan, Y., et al. (2009). Upgrading root physiology for stress tolerance by ectomycorrhizas: insights from metabolite and transcriptional profiling into reprogramming for stress anticipation. Plant Physiol. 151, 1902-1917. doi: 10.1104/pp.109. 143735

MacLean, A. M., Bravo, A., and Harrison, M. J. (2017). Plant signaling and metabolic pathways enabling arbuscular mycorrhizal symbiosis. Plant Cell 29, 2319-2335. doi: 10.1105/tpc. 17.00555

Magoc, T., and Salzberg, S. L. (2011). FLASH: fast length adjustment of short reads to improve genome assemblies. Bioinformatics 27, 2957-2963. doi: 10.1093/ bioinformatics/btr507

Marozzi, G., Sanchez, S., Benucci, G. M., Bonito, G., Falini, L. B., Albertini, E., et al. (2017). Mycorrhization of pecan (Carya illinoinensis) with black truffles: Tuber melanosporum and Tuber brumale. Mycorrhiza 27, 303-309. doi: 10.1007/s00572-016-0743-y

Martin, F., Kohler, A., Murat, C., Veneault-Fourrey, C., and Hibbett, D. S. (2016). Unearthing the roots of ectomycorrhizal symbioses. Nat. Rev. Microbiol. 14, 760-773. doi: 10.1038/nrmicro.2016.149

Mechri, B., Attia, F., Tekaya, M., Cheheb, H., and Hammami, M. (2014). Colonization of olive trees (Olea europaea L.) with the arbuscular mycorrhizal fungus Glomus sp. modified the glycolipids biosynthesis and resulted in accumulation of unsaturated fatty acids. J. Plant Physiol. 171, 1217-1220. doi: 10.1016/j.jplph.2014.04.005

Mello, A., Ding, G. C., Piceno, Y. M., Napoli, C., Tom, L. M., DeSantis, T. Z., et al. (2013). Truffle brûlés have an impact on the diversity of soil bacterial communities. PLoS One 8:e61945. doi: 10.1371/journal.pone. 0061945

Mello, A., Lumini, E., Napoli, C., Bianciotto, V., and Bonfante, P. (2015). Arbuscular mycorrhizal fungal diversity in the Tuber melanosporum brule. Fungal Biol. 119, 518-527. doi: 10.1016/j.funbio.2015.02.003

Mucha, J., Guzicka, M., Ratajczak, E., and Zadworny, M. (2014). Strategies utilized by trophically diverse fungal species for Pinus sylvestris root colonization. Tree Physiol. 34, 73-86. doi: 10.1093/treephys/tpt111

Napoli, C., Mello, A., Borra, A., Vizzini, A., Sourzat, P., and Bonfante, P. (2010). Tuber melanosporum, when dominant, affects fungal dynamics in truffle grounds. New Phytol. 185, 237-247. doi: 10.1111/j.1469-8137.2009.03053.x

Nguyen, N. H., Song, Z., Bates, S. T., Branco, S., Tedersoo, L., Menke, J., Schilling, J. S., et al. (2016). FUNGuild: an open annotation tool for parsing fungal community datasets by ecological guild. Fungal Ecol. 20, 241-248. doi: 10.1016/ j.funeco.2015.06.006

Pacioni, G., Cerretani, L., Procida, G., and Cichelli, A. (2014). Composition of commercial truffle flavored oils with GC-MS analysis and discrimination with an electronic nose. Food Chem. 146, 30-35. doi: 10.1016/j.foodchem.2013. 09.016

Payen, T., Murat, C., and Martin, F. (2016). Reconstructing the evolutionary history of gypsy retrotransposons in the Perigord black truffle (Tuber melanosporum Vittad.). Mycorrhiza 26, 553-563. doi: 10.1007/s00572-0160692-5

Pérez-de-Luque, A., Tille, S., Johnson, I., Pascual-Pardo, D., Ton, J., and Cameron, D. D. (2017). The interactive effects of arbuscular mycorrhiza and plant growthpromoting rhizobacteria synergistically enhance host plant defences against pathogens. Sci. Rep. 7:16409. doi: 10.1038/s41598-017-16697-4 
Poma, A., Limongi, T., and Pacioni, G. (2006). Current state and perspectives of truffle genetics and sustainable biotechnology. Appl. Microbiol. Biotechnol. 72, 437-441. doi: 10.1007/s00253-006-0519-y

Rao, G., Sui, J., and Zhang, J. (2016). Metabolomics reveals significant variations in metabolites and correlations regarding the maturation of walnuts (Juglans regia L.). Biol. Open 5, 829-836. doi: 10.1242/bio.017863

Rasmussen, S., Parsons, A. J., and Jones, C. S. (2012). Metabolomics of forage plants: a review. Ann. Bot. 110, 1281-1290. doi: 10.1093/aob/mcs023

Saia, S., Ruisi, P., Fileccia, V., Di Miceli, G., Amato, G., and Martinelli, F. (2015). Metabolomics suggests that soil inoculation with arbuscular mycorrhizal fungi decreased free amino acid content in roots of durum wheat grown under N-Limited, P-Rich field conditions. PLoS One 10:e0129591. doi: 10.1371/ journal.pone.0129591

Salerni, E., Iotti, M., Leonardi, P., Gardin, L., D’aguanno, M., Perini, C., et al. (2014). Effects of soil tillage on Tuber magnatum development in natural truffieres. Mycorrhiza 24(Suppl. 1), S79-S87. doi: 10.1007/s00572-013-0543-6

Scervino, J. M., Ponce, M. A., Erra-Bassells, R., Vierheilig, H., Ocampo, J. A., and Godeas, A. (2005). Arbuscular mycorrhizal colonization of tomato by Gigaspora and Glomus species in the presence of root flavonoids. J. Plant Physiol. 162, 625-633. doi: 10.1016/j.jplph.2004.08.010

Schmidberger, P. C., and Schieberle, P. (2017). Characterization of the key aroma compounds in white alba truffle (Tuber magnatum pico) and Burgundy Truffle (Tuber uncinatum) by means of the sensomics approach. J. Agric. Food Chem. 65, 9287-9296. doi: 10.1021/acs.jafc.7b04073

Schweiger, R., Baier, M. C., Persicke, M., and Muller, C. (2014). High specificity in plant leaf metabolic responses to arbuscular mycorrhiza. Nat. Commun. 5:3886. doi: $10.1038 /$ ncomms 4886

Schweiger, R., and Muller, C. (2015). Leaf metabolome in arbuscular mycorrhizal symbiosis. Curr. Opin. Plant Biol. 26, 120-126. doi: 10.1016/j.pbi.2015.06.009

Selosse, M. A., Richard, F., He, X., and Simard, S. W. (2006). Mycorrhizal networks: des liaisons dangereuses? Trends Ecol. Evol. 21, 621-628.

Shah, F., Nicolas, C., Bentzer, J., Ellstrom, M., Smits, M., Rineau, F., et al. (2016). Ectomycorrhizal fungi decompose soil organic matter using oxidative mechanisms adapted from saprotrophic ancestors. New Phytol. 209, 1705-1719. doi: $10.1111 /$ nph. 13722

Splivallo, R., Fischer, U., Gobel, C., Feussner, I., and Karlovsky, P. (2009). Truffles regulate plant root morphogenesis via the production of auxin and ethylene. Plant Physiol. 150, 2018-2029. doi: 10.1104/pp.109.141325

Streiblova, E., Gryndlerova, H., and Gryndler, M. (2012). Truffle brule: an efficient fungal life strategy. FEMS Microbiol. Ecol. 80, 1-8. doi: 10.1111/j.1574-6941. 2011.01283.x

Taschen, E., Sauve, M., Taudiere, A., Parlade, J., Selosse, M. A., and Richard, F. (2015). Whose truffle is this? Distribution patterns of ectomycorrhizal fungal diversity in Tuber melanosporum brules developed in multi-host Mediterranean plant communities. Environ. Microbiol. 17, 2747-2761. doi: 10.1111/1462-2920. 12741

Tian, H., Yuan, X., Duan, J., Li, W., Zhai, B., and Gao, Y. (2017). Influence of nutrient signals and carbon allocation on the expression of phosphate and nitrogen transporter genes in winter wheat (Triticum aestivum L.) roots colonized by arbuscular mycorrhizal fungi. PLoS One 12:e0172154. doi: 10.1371/journal.pone.0172154

Tschaplinski, T. J., Plett, J. M., Engle, N. L., Deveau, A., Cushman, K. C., Martin, M. Z., et al. (2014). Populus trichocarpa and Populus deltoides exhibit different metabolomic responses to colonization by the symbiotic fungus Laccaria bicolor. Mol. Plant Microbe Interact. 27, 546-556. doi: 10.1094/MPMI-09-130286-R

Vahdatzadeh, M., Deveau, A., and Splivallo, R. (2015). The role of the microbiome of truffles in aroma formation: a meta-analysis approach. Appl. Environ. Microbiol. 81, 6946-6952. doi: 10.1128/AEM.01098-15

Valverde-Asenjo, I., Garcia-Montero, L. G., Quintana, A., and Velazquez, J. (2009). Calcareous amendments to soils to eradicate Tuber brumale from $T$. melanosporum cultivations: a multivariate statistical approach. Mycorrhiza 19, 159-165. doi: 10.1007/s00572-008-0224-z

Vayssieres, A., Pencik, A., Felten, J., Kohler, A., Ljung, K., Martin, F., et al. (2015). Development of the poplar-laccaria bicolor ectomycorrhiza modifies root auxin metabolism, signaling, and response. Plant Physiol. 169, 890-902. doi: 10.1104/ pp.114.255620

Vita, F., Taiti, C., Pompeiano, A., Bazihizina, N., Lucarotti, V., Mancuso, S., et al. (2015). Volatile organic compounds in truffle (Tuber magnatum Pico): comparison of samples from different regions of Italy and from different seasons. Sci. Rep. 5:12629. doi: 10.1038/srep12629

Wang, Q., Garrity, G. M., Tiedje, J. M., and Cole, J. R. (2007). Naive bayesian classifier for rapid assignment of rRNA sequences into the new bacterial taxonomy. Appl. Environ. Microbiol. 73, 5261-5267. doi: 10.1128/AEM. 00062-07

Watts-Williams, S. J., and Cavagnaro, T. R. (2015). Using mycorrhiza-defective mutant genotypes of non-legume plant species to study the formation and functioning of arbuscular mycorrhiza: a review. Mycorrhiza 25, 587-597.

Weckwerth, W., Wenzel, K., and Fiehn, O. (2004). Process for the integrated extraction, identification and quantification of metabolites, proteins and RNA to reveal their co-regulation in biochemical networks. Proteomics 4, 78-83. doi: 10.1002/pmic.200200500

Xiao, C., Feng, S., Wang, H., Gong, Z., and Ng, T. (2014). Purification and characterization of a ribonuclease with antiproliferative activity from the mystical wild mushroom Tuber indicum. J. Basic Microbiol. 54(Suppl. 1), S102-S108. doi: 10.1002/jobm.201300018

Yanan, W., Xusheng, Z., Baozhong, Y., Wenchao, Z., and Jintang, G. (2015). Biochemical defenses induced by mycorrhizae fungi glomus mosseae in controlling strawberry fusarium wilt. Open Biomed. Eng. J. 9, 301-304. doi: 10.2174/1874120701509010301

Yang, Y., He, C., Huang, L., Ban, Y., and Tang, M. (2017). The effects of arbuscular mycorrhizal fungi on glomalin-related soil protein distribution, aggregate stability and their relationships with soil properties at different soil depths in lead-zinc contaminated area. PLoS One 12:e0182264. doi: 10.1371/journal.pone. 0182264

Yu, F., Wang, D., Yi, X., Shi, X., Huang, Y., Zhang, H., et al. (2014). Does animalmediated seed dispersal facilitate the formation of Pinus armandii-Quercus aliena var. acuteserrata forests?. PLoS One 9:e89886. doi: 10.1371/journal.pone. 0089886

Zampieri, E., Chiapello, M., Daghino, S., Bonfante, P., and Mello, A. (2016). Soil metaproteomics reveals an inter-kingdom stress response to the presence of black truffles. Sci. Rep. 6:25773. doi: 10.1038/srep 25773

Zhao, W., Wang, X. H., Li, H. M., Wang, S. H., Chen, T., Yuan, Z. P., et al. (2014). Isolation and characterization of polysaccharides with the antitumor activity from Tuber fruiting bodies and fermentation system. Appl. Microbiol. Biotechnol. 98, 1991-2002. doi: 10.1007/s00253-0135379-7

Zhou, Z., Meng, H., Liu, Y., Gu, J. D., and Li, M. (2017). Stratified bacterial and archaeal community in mangrove and intertidal wetland mudflats revealed by high throughput 16S rRNA gene sequencing. Front. Microbiol. 8:2148. doi: $10.3389 /$ fmicb. 2017.02148

Zitouni-Haouar, F. H., Fortas, Z., and Chevalier, G. (2014). Morphological characterization of mycorrhizae formed between three Terfezia species (desert truffles) and several Cistaceae and Aleppo pine. Mycorrhiza 24, 397-403. doi: 10.1007/s00572-013-0550-7

Zlotorynski, E. (2016). DNA repair: the cell cycle flavours of repair. Nat. Rev. Genet. 17:65. doi: $10.1038 / \mathrm{nrg} .2015 .35$

Conflict of Interest Statement: The authors declare that the research was conducted in the absence of any commercial or financial relationships that could be construed as a potential conflict of interest.

Copyright (c) 2018 Li, Yan, Ye, Zhou, Zhang, Peng, Zhang and Li. This is an openaccess article distributed under the terms of the Creative Commons Attribution License (CC BY). The use, distribution or reproduction in other forums is permitted, provided the original author(s) and the copyright owner(s) are credited and that the original publication in this journal is cited, in accordance with accepted academic practice. No use, distribution or reproduction is permitted which does not comply with these terms. 